\title{
Global mRNA and miRNA Analysis Reveal Key Processes in the Initial Response to Infection with WSSV in the Pacific Whiteleg Shrimp
}

\author{
Rebecca S. Millard ${ }^{1,2, *}$, Lisa K. Bickley ${ }^{1,2}$, Kelly S. Bateman 2,3®D, Audrey Farbos ${ }^{4}$, Diana Minardi ${ }^{3}{ }^{(D)}$, \\ Karen Moore ${ }^{4}$, Stuart H. Ross ${ }^{2,3}$, Grant D. Stentiford ${ }^{2,3}$, Charles R. Tyler 1,2, Ronny van Aerle ${ }^{2,3,+}$ (D) \\ and Eduarda M. Santos $1,2, *,+$ \\ 1 Biosciences, College of Life and Environmental Sciences, University of Exeter, Exeter EX4 4QD, UK; \\ L.K.Bickley@exeter.ac.uk (L.K.B.); C.R.Tyler@exeter.ac.uk (C.R.T.) \\ 2 Centre for Sustainable Aquaculture Futures, University of Exeter, Exeter EX4 4QD, UK; \\ kelly.bateman@cefas.co.uk (K.S.B.); stuart.ross@cefas.co.uk (S.H.R.); grant.stentiford@cefas.co.uk (G.D.S.); \\ ronny.vanaerle@cefas.co.uk (R.v.A.) \\ 3 Cefas Weymouth Laboratory, International Centre of Excellence for Aquatic Animal Health, \\ Weymouth DT4 8UB, UK; diana.minardi@cefas.co.uk \\ 4 Exeter Sequencing Service, Geoffrey Pope Building, University of Exeter, Exeter EX4 4QD, UK; \\ A.Farbos@exeter.ac.uk (A.F.); K.A.Moore@exeter.ac.uk (K.M.) \\ check for \\ updates \\ Citation: Millard, R.S.; Bickley, L.K.; \\ * Correspondence: rm527@exeter.ac.uk (R.S.M.); e.santos@exeter.ac.uk (E.M.S.); \\ Tel.: +44-(0)-1392-724607 (E.M.S.) \\ $+\quad$ These authors contributed equally to this work.
} Bateman, K.S.; Farbos, A.; Minardi, D.; Moore, K.; Ross, S.H.; Stentiford, G.D.; Tyler, C.R.; van Aerle, R.; et al. Global mRNA and miRNA Analysis Reveal Key Processes in the Initial Response to Infection with WSSV in the Pacific Whiteleg Shrimp. Viruses 2021, 13, 1140. https://doi.org/ $10.3390 / \mathrm{v} 13061140$

\section{Academic Editors: Manfred}

Weidmann, Mansour El-Matbouli, Sven M. Bergmann and Weiwei Zeng

Received: 1 May 2021

Accepted: 10 June 2021

Published: 13 June 2021

Publisher's Note: MDPI stays neutral with regard to jurisdictional claims in published maps and institutional affiliations.

Copyright: (c) 2021 by the authors. Licensee MDPI, Basel, Switzerland. This article is an open access article distributed under the terms and conditions of the Creative Commons Attribution (CC BY) license (https:// creativecommons.org/licenses/by/ $4.0 /)$.

\begin{abstract}
White Spot Disease (WSD) presents a major barrier to penaeid shrimp production. Mechanisms underlying White Spot Syndrome Virus (WSSV) susceptibility in penaeids are poorly understood due to limited information related to early infection. We investigated mRNA and miRNA transcription in Penaeus vannamei over $36 \mathrm{~h}$ following infection. Over this time course, 6192 transcripts and 27 miRNAs were differentially expressed-with limited differential expression from 3-12 h post injection (hpi) and a more significant transcriptional response associated with the onset of disease symptoms (24 hpi). During early infection, regulated processes included cytoskeletal remodelling and alterations in phagocytic activity that may assist WSSV entry and translocation, novel miRNAinduced metabolic shifts, and the downregulation of ATP-dependent proton transporter subunits that may impair cellular recycling. During later infection, uncoupling of the electron transport chain may drive cellular dysfunction and lead to high mortalities in infected penaeids. We propose that post-transcriptional silencing of the immune priming gene Dscam (downregulated following infections) by a novel shrimp miRNA (Pva-pmiR-78; upregulated) as a potential mechanism preventing future recognition of WSSV that may be suppressed in surviving shrimp. Our findings improve our understanding of WSD pathogenesis in P. vannamei and provide potential avenues for future development of prophylactics and treatments.
\end{abstract}

Keywords: aquaculture; invertebrate; transcriptome; RNA-seq

\section{Introduction}

Aquaculture is an important industry for global food security. Farmed crustaceans currently account for approximately $11 \%$ of total aquaculture production by volume and $28 \%$ by value [1]. Penaeid shrimp register highly in terms of quantity and value; the Pacific whiteleg shrimp (Penaeus vannamei) being the most widely farmed species in an industry valued at approximately US\$30 billion [1]. Most shrimp are farmed at high density and there are continued efforts to intensify this further. This intensification, and the regular and extensive movement of shrimp larvae and broodstock between aquaculture sites, have resulted in the rapid emergence and spread of pathogens. Losses due to disease may 
exceed $40 \%$ of global capacity annually [2]. Consequently, disease is considered one of the greatest factors limiting productivity and future expansion of shrimp aquaculture [3] with approximately $60 \%$ of these losses being attributable to viral diseases [4].

White Spot Syndrome Virus (WSSV) has inflicted an estimated US $\$ 21$ billion loss in the farmed shrimp industry since its emergence in 1992 [2]. The virus spreads swiftly through aquatic ecosystems and international trade has facilitated its spread to all major shrimp farming areas of the world. Despite significant research efforts on WSSV, effective treatments are not yet widely available to limit its impact. Following infection with WSSV, progression to disease occurs rapidly (3-10 days), leading to high mortality $(90-100 \%)$ in production systems [5].

Understanding the molecular interactions between the host and the pathogen following infection, particularly during the early stages, could aid in the development of White Spot Disease (WSD) treatments and prophylactics. Applying sequencing technologies to the study of WSSV pathogenesis enables insights into the changes of both the viral and host genomes and facilitates understanding of host-pathogen interactions. Multiple WSSV genomes have been sequenced [6-13], which have enhanced our understanding of WSSV gene expression, genome evolution, and disease epidemiology. Next-generation sequencing has been applied to study the responses of penaeid shrimp to WSSV infection with decreasing costs, increasing the technology's accessibility [14]. Currently, transcriptomic data associated with WSSV infection are available for P. vannamei [15-19], Kuruma prawn Penaeus japonicus [20], and Chinese shrimp Penaeus chinensis [21,22]. These studies have contributed to our understanding of the transcriptional responses during acute and latent infections, upon imminent death, and in response to combined infection and temperature stressors. An initial study into the temporal dynamics of global gene transcription during WSSV infection reported dynamic, time-dependent alterations of cytoskeletal, metabolic, immune, and apoptotic processes at 1.5, 18, and $54 \mathrm{~h}$ post injection (hpi) [17]. Despite this, our understanding, both when considering the gills-one of the initial sites of infection of WSSV in shrimp [23] — and the early hours/phase of WSSV infection, remains limited.

Invertebrate miRNAs form a key component of the innate immune system and antiviral response [24], and are also widely recognised as important factors mediating the progression of disease [25-28], including the replication of viruses [29-33]. The miRNA responses of multiple crustacean species including P. japonicus [34], P. chinensis [35], Penaeus monodon [36], P. vannamei [37-39], Cherax quadricarinatus [40], and Procambarus clarkii [41] to WSSV have been studied. Despite this, miRNA expression profiles of the gill tissue, which is a primary site of WSSV infection, has been largely overlooked until recently [37,39] and critically, previously published studies lack detailed temporal information regarding the miRNA expression changes in response to very early WSSV infection.

Here we sought to further the molecular understanding of the host-pathogen interactions between WSSV and P. vannamei through studying the temporal dynamics of global transcriptional changes, both mRNA and miRNA, following WSSV infection. In our approach (encompassing temporal changes from the early stages of infection; adopting the recommended specific-pathogen-free (SPF) homogenate control injections [16]; and without the need for pooling individual samples for sequencing [42]), we employ RNA sequencing technology to generate a detailed global transcriptome from the gills of WSSVinfected P. vannamei, with mRNA and miRNA transcriptional datasets derived from the same biological samples. Our results reveal transcriptomic responses occurring in the earliest stages of interaction between WSSV and its host.

\section{Materials and Methods}

\subsection{Virus Inoculum Preparation}

WSSV isolate (UAZ 00-173B), from the University of Arizona, Tucson, Arizona, USA, OIE reference laboratory for WSSV, that retained virulence through passages in specificpathogen-free (SPF) P. vannamei at Cefas Weymouth laboratory was used. Inoculums were generated as previously described [43] by passaging WSSV in P. vannamei, and 
homogenising uninfected and WSSV-infected shrimp in $2 \%$ sterile saline to generate SPFand WSSV-homogenates (infection was confirmed using histopathology and nested PCR). Homogenates were centrifuged at $5000 \times \mathrm{g}$ for $20 \mathrm{~min}$ at $4{ }^{\circ} \mathrm{C}$ to pellet cellular debris and the supernatants were diluted 1:20 in sterile saline and filtered using a $0.2 \mu \mathrm{m}$ syringe filter (Sartorius Stedim Biotech GmbH (Göttingen, Germany)). The WSSV inoculum contained approximately $2.72 \times 10^{7}$ virions $/ \mathrm{mg}$ (quantified by qPCR).

\subsection{Disease Trial}

Sixty shrimp $(5.0 \pm 1.5 \mathrm{~g}$ standard deviation) were divided into two treatment groups and injected with either SPF or WSSV-infected shrimp inoculum at a dosage of $10 \mu \mathrm{L} \mathrm{g}^{-1}$ (wet body weight). This corresponded to an average of $6.80 \times 10^{7}$ virions per shrimp. Four unexposed shrimp from an additional control tank were sampled at $0 \mathrm{~h}$ to provide a histological control independent of the disease trial. Shrimp were regularly checked throughout the disease trial and moribund shrimp removed to limit virus transmission via cannibalism. Two shrimp were sampled from each tank at 3, 6, 9, 12, 24, and $36 \mathrm{~h}$ post injection (hpi) totalling 4 shrimp per treatment and timepoint (Figure 1). Shrimp were euthanised on ice for $10 \mathrm{~min}$ prior to dissection in which the gills from the left-hand side of the shrimp were removed, snap-frozen in liquid nitrogen, and stored at $-80{ }^{\circ} \mathrm{C}$ for transcriptome profiling. Two anterior pleopods were removed and stored in absolute ethanol for quantification of viral load and the remaining carcasses were fixed immediately for histopathology analysis by injecting Davidson's seawater fixative at regular intervals along their lengths and submerging them in fixative for $24 \mathrm{~h}$.

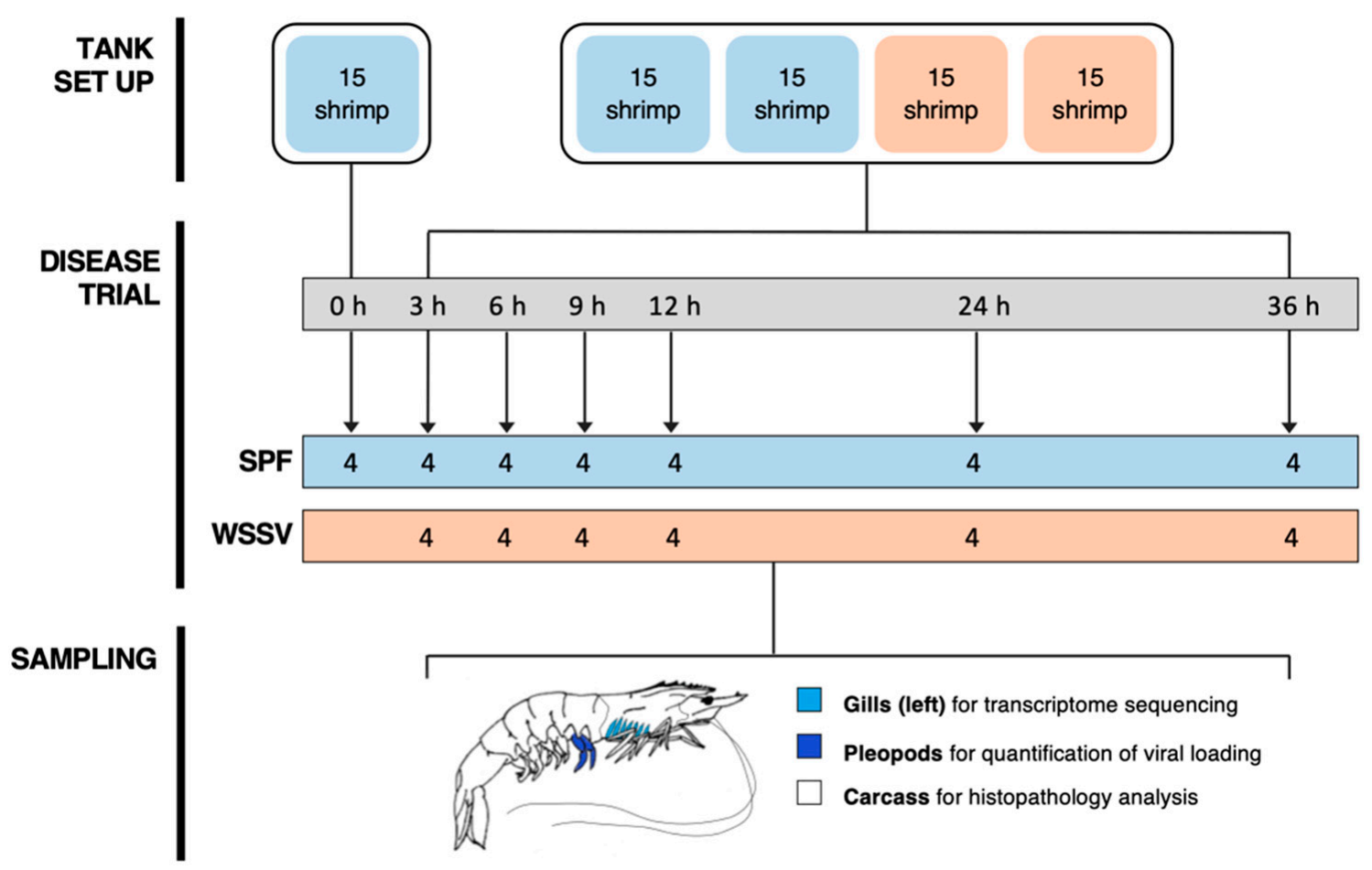

Figure 1. Schematic of the WSSV injection trial experimental set-up and sampling. Pacific whiteleg shrimp were randomly allocated into two groups. At zero hours, four control shrimp were sampled from a separate tank to provide a time-zero histological control reference. The remaining shrimp were injected with either specific-pathogen-free (SPF) or WSSV-infected shrimp inoculum. Four shrimp (two per treatment tank) were sampled from each treatment group at subsequent timepoints: $3,6,9,12,24$, and $36 \mathrm{~h}$. At each sampling point, gills from the left side of the shrimp were dissected and snap-frozen for transcriptome sequencing. The two most anterior pleopods were sampled to quantify viral loading, and the remaining carcass was fixed for histological analysis. 


\subsection{Infection Confirmation and Viral Load Quantification}

To confirm the presence/absence of WSSV infection in each treatment group, histopathological examination was performed. Following fixation, shrimp carcasses were transferred to $70 \%$ IMS and sectioned in order to fit within standard histology cassettes and reveal the main organs of interest (gill, gut, and cuticular epithelium). Samples were further processed according to previous standard methods [43]. Viral load was quantified by qPCR on DNA extracted from pleopods (20-45 mg) using the EZ1 DNA Tissue kit and BioRobot ${ }^{\circledR}$ EZ1 (Qiagen (Hilden, Germany)). Briefly, pleopods were homogenised in 1:10 w/v tissue to G2 buffer (Qiagen (Hilden, Germany)) with Lysing Matrix FastPrep ${ }^{\circledR}$ A tubes and a FastPrep ${ }^{\circledR}$ cell disrupter $(1 \mathrm{~min}$ at $5 \mathrm{~m} / \mathrm{s})$, followed by overnight digestion with proteinase $\mathrm{K}(10 \mu \mathrm{L}$ at $10 \mu \mathrm{g} / \mathrm{mL})$ at $56^{\circ} \mathrm{C}$. qPCR conditions and positive control plasmid preparation followed previously published methods [44], using $20 \mu \mathrm{L}$ reactions and $2.5 \mu \mathrm{L}$ of DNA. Reactions were performed in triplicates and included negative controls with molecular grade water instead of DNA. Quantification was performed by generating standard curves with dilution series of $4 \times 10^{7}$ copies/ $\mu \mathrm{L}$ of plasmids. qPCR reactions were performed on an ABI Biosystems TaqMan machine and copy numbers calculated with StepOne ${ }^{\mathrm{TM}}$ Software v2.3 (Applied Biosystems (Waltham, MA, USA)).

\subsection{RNA Extraction, Library Preparation, and Sequencing}

Total RNA was extracted from gills $(\mathrm{n}=48)$ using the miRNeasy Mini Kit (Qiagen (Hilden, Germany)) with on-column DNase I (Qiagen (Hilden, Germany)) treatment to remove DNA contaminants. RNA quality was assessed via Tapestation using the RNA Analysis ScreenTape System (Agilent (Santa Clara, CA, USA)). mRNA libraries were prepared using the TruSeq stranded mRNA sample preparation kit with TruSeq A and B adapter sets (Illumina (San Diego, CA, USA)) to enable multiplexing of the 48 libraries into two pools. An equal number of control and WSSV-injected samples from each timepoint were randomly allocated to each library pool. These were sequenced on an Illumina HiSeq 2500 to $100 \mathrm{bp}$ in paired-end mode. miRNA-seq libraries were constructed using the NEXTFlex ${ }^{\mathrm{TM}}$ small RNA sequencing kit v3 (Bioo Scientific Corporation (Austin, TX, USA)) with 18 PCR amplification cycles and gel-free size selection protocol. The final pooled library was size selected using the Sage Pippin Prep System (Sage Science (Beverly, MA, USA)) and sequenced to $50 \mathrm{bp}$ in single read mode on the Illumina HiSeq 2500.

\subsection{Transcriptome Analysis}

Detailed steps for transcriptomic analysis are given in Figure S1. Briefly, raw reads were subject to quality assessments and trimmed with trimmomatic v0.36 [45] to remove adapters, short reads, and low-quality bases. Trinity v2.4.0 [46] was used to de novo assemble the transcriptome, and transcript redundancy was reduced with CD-HIT-EST v4.6 [47]. Transcriptome assembly metrics including mean contig length, Ex90N50, BUSCO (v2.0) scores [48], and read representation were used to assess the quality of the assembly. Transcripts were annotated using the BlastX algorithm of Diamond v0.8.27 [49] and the RefSeq Release 85 protein database using an e-value cut-off of $1 \times 10^{-5}$ with sensitive mode enabled. Hits were filtered taxonomically using MEGAN Community Edition v6.6.0 [50] and transcripts from metazoan and viral clades, which were assumed to have arisen from the host and the virus, respectively, were extracted. Trimmed reads were then aligned to the filtered transcriptome using Bowtie v1.1.2 [51] and transcript abundance was estimated using RSEM v1.3.0 [52]. Differentially expressed transcripts were identified by comparing WSSV-injected shrimp with their time matched controls using edgeR v3.16.3 [53] with a false discovery rate (FDR) cut-off of 0.05 [54]. Trends in the dataset were identified by principal component analysis using the Trinity PtR script with the complete transcript counts table. Gene ontology (GO) terms were assigned to transcripts within Blast2Go PRO v5.0 [55] and enriched GO terms identified using Gene Set Enrichment Analysis (GSEA) software [56] with 1000 permutations, minimum gene set size of two, and a significance cut-off of 0.05. Kyoto Encyclopaedia of Genes and Genomes (KEGG) pathway annotations 
were retrieved by inputting Drosophila melanogaster transcript homologs identified by a Diamond BlastX search of differentially expressed shrimp transcripts against the Uniprot $D$. melanogaster complete proteome (e-value $1 \times 10^{-20}$ ) into the KEGG Automatic Annotation Server (KAAS) v2.1 (release 86.1) [57] with bi-directional best hits. KEGG pathway representation was then assessed using the Generally Applicable Gene-set/Pathway Analysis (GAGE) package v3.9 [58] in R v3.6 [59] with D. melanogaster dataset as background and a significance cut-off of 0.05. Expression data were overlaid on KEGG pathways using Pathview v3.9 [60]. Finally, the presence of the replicating virus was detected in each sample by aligning trimmed reads against the WSSV-CN (GenBank Accession: AF332093.3 [61]) genome sequence using Bowtie2 [62]. Where more than $1 \%$ of the total sequencing reads were aligned to WSSV-CN, the virus was deemed to be present and replicating.

\section{6. miRNA Analysis}

A detailed description of tools and parameters used in the analysis of small RNA sequences is provided in Figure S2. Raw small RNA sequences were quality trimmed to remove adapter sequences (including randomised 4 nt adapter signatures incorporated during library preparation), and sequences outside the expected length range of miRNAs (18-26 nt) using Cutadapt v2.1 [63]. Trimmed reads aligned to the P. vannamei ribosomal RNA sequence (GenBank Accession: AF124597.1) with Bowtie v1.0.0 [51] were removed using Samtools v1.4 [64] and Seqtk v1.2-r94 [65]. Reads with more than 50\% of their lengths comprised of low complexity sequences (e.g., homopolymers) were also removed using the Fqtrim v0.9.7 DUST filter [66]. The miRDeep2 v2.0.0.8 [67] pipeline was employed to collapse reads, align reads to the $P$. vannamei genome (GenBank Accession: QCYY00000000.1 [68]), predict, and quantify miRNAs. miRNA predictions were guided by mature miRNA sequences from Tribolium castaneum $(\mathrm{n}=211)$ from the miRGeneDB database [69] and miRNAs identified in closely related Penaeus japonicus $(\mathrm{n}=63)$ [70]. miRNAs with Rfam hits were removed and the redundancy was reduced using CD-HIT-EST v4.8.1 [47] prior to quantification. miRNAs were annotated using BlastN [71] optimised for sequences $<30 \mathrm{nt}$ with an e-value of $1 \times 10^{-5}$ against the previously described $P$. vannamei miRNAs [72], P. japonicus miRNAs [70], as well as T. castaneum, D. melanogaster, and Daphnia pulex miRNAs from the miRGeneDB database [69]. Due to the highly conserved nature of miRNAs, predicted miRNAs with hits were classified as known homologs whilst those with no annotation were considered novel. Novel P. vannamei miRNAs were labelled as putative miRNAs with 'pmiR' and assigned a unique number. Differentially expressed miRNAs were identified between WSSV-injected shrimp and time-matched controls using DESeq2 v3.9 [73] with a Benjamin-Hochberg-adjusted significance cut-off of 0.05 [54]. miRNA secondary structures were predicted using RNAfold v2.4.11 [74] and their folding stability was predicted with randfold [75]. Details of the WSSV miRNA analyses are specified within Appendix A.

\subsection{Integrated Analysis of RNA-Seq and miRNA-Seq}

To determine the functionality of differentially expressed miRNAs, the ability of these to bind to transcripts within the assembled transcriptome was predicted using miRanda v3.3a [76] and RNA22 v2 [77] specifying strict alignment in the seed region and a minimum free energy score less than $-20 \mathrm{kcal} / \mathrm{mol}$. As per recommended best practice [78], interactions that were predicted by both tools were considered potential targets. Enriched GO terms were identified within the lists of predicted target transcripts for each differentially expressed miRNA within Blast2Go PRO v5.0 [55] using a Fisher's Exact test with an adjusted significance cut-off of 0.05 . The relative expression of differentially expressed miRNAs and target transcripts of interest that were associated with significantly enriched GO terms was plotted and compared. Plots were generated in R using ggplot2 [79]; all error bars represent \pm one standard error of the mean. 


\section{Results}

\subsection{Disease Presentation}

Control shrimp remained apparently healthy throughout the experiment, displaying no visible signs of disease. However, two shrimp (one at $12 \mathrm{hpi}$ and another at $24 \mathrm{hpi}$ ) died during the study, likely attributable to handling stress following the sham injection. In the WSSV treatment group, shrimp displayed histopathological symptoms of infection from $24 \mathrm{hpi}$, with mortalities occurring at $24 \mathrm{hpi}(\mathrm{n}=3)$ and at $36 \mathrm{hpi}(\mathrm{n}=3)$, which coincided with an exponential increase in viral copy number and pathognomonic signs of disease observed with histopathology (Figure 2).

\subsection{Sequencing and Transcriptome Assembly}

Sequencing produced $698,628,573$ paired-end reads $(2 \times 100 \mathrm{bp})$, averaging $14,554,762$ read pairs per individual shrimp sample. A transcriptome was de novo assembled using $660,175,443$ quality-trimmed reads to produce 116,801 reduced-redundancy transcripts (87,774 loci). The transcriptome had an N50 of $1255 \mathrm{bp}$, Ex90N50 of $2220 \mathrm{bp}$, mean transcript length of $760 \mathrm{bp}$, and on average $98.0 \%$ of the reads from each sample were represented within the transcriptome. In addition, the present transcriptome was near-complete, containing $97.7 \%$ of Arthropoda BUSCO's as either single $(80.3 \%)$ or duplicated copies $(17.4 \%)$ with few present as fragments $(0.8 \%)$ or missing $(1.5 \%)$. The RefSeq complete protein database (release 85 ) was used to assign annotations to $25,813(22.1 \%)$ transcripts, which were subsequently filtered to retain only Metazoan $(23,879)$ and Viral $(194)$ transcripts assumed to have derived from the host and from WSSV, respectively. Within the Metazoan taxon, the Pancrustacea $(14,619)$ were the most strongly represented group.

\subsection{Transcript Expression Analysis}

In total, 6192 transcripts were differentially expressed in at least one timepoint between WSSV and the time-matched controls. The number of differentially expressed transcripts followed a biphasic pattern with low numbers during very early infection ( $\leq 670$ per timepoint from 3-12 hpi) and substantially higher numbers during later infection ( $\geq 3709$ per timepoint at 24 and $36 \mathrm{hpi}$ ) (Figure 3A). Large transcriptional changes during later timepoints coincided with the appearance of clinical signs of disease and rapid onset of mortality (Figure 2). In addition, the proportion of WSSV-derived sequences in WSSV-injected shrimp increased from $0.03 \%$ (3 hpi) to $13.2 \%$ (12 hpi), reaching a peak of $38.1 \%$ of transcripts at 24 hpi (Figure 3B). A principal component analysis (PCA) of differentially expressed transcripts demonstrated minimal variation in control treatments that clustered together in the first principal component (PC1) (Figure 3C). In contrast, WSSV-injected shrimp separated along PC1 according to time post injection, except for late timepoints (24 and $36 \mathrm{hpi}$ ), the differential expression profiles of which were not sufficiently different to cluster separately. A large amount of variation attributed to PC2 was also observed, likely due to the effect of handling animals during injection-highlighting the importance of time-matched controls. A full list of differentially expressed transcripts is presented in Datasets S1 to S6. 

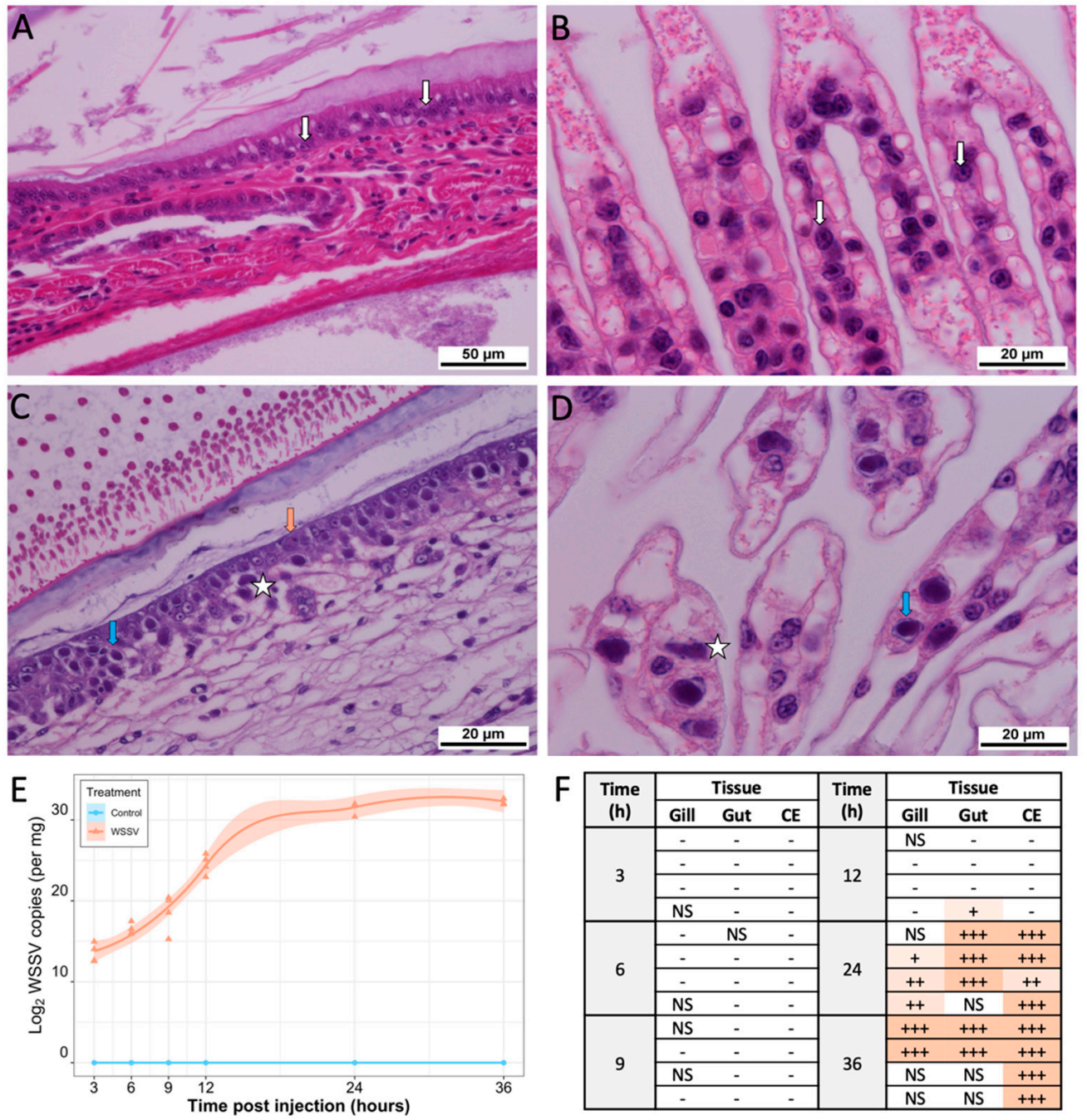

Figure 2. Phenotypic evidence for infection status in control and WSSV-injected treatments. Shrimp from control and WSSV-injected groups were subjected to histological screening, using haematoxylin and eosin staining with light microscopy, for signs of WSSV infection in the gill, gut, and cuticular epithelium tissue. (A) Control gut and (B) control gill tissues contain small, regularly shaped nuclei with basophilic stain (white arrow). (C) Nuclei infected with WSSV in the gut and (D) gills were enlarged. During early infection their chromatin was marginalised and large inclusion bodies stained homogeneous eosinophilic (orange arrow). As the infection progressed, these inclusions became increasingly basophilic (blue arrow) before disintegrating so that the contents fused with the cytoplasm (left of white star). (E) Scatter plot with smoothed conditional local regression line depicting log2 WSSV copy number over time, measured by qPCR. Shaded areas represent 95\% confidence interval. (F) Table depicting the infection status of gill, gut, and cuticular epithelium (CE) tissue of WSSV-injected shrimp at each timepoint following WSSV injection. No infection is denoted by "-", mild infection (few enlarged nuclei present) by " + ", moderate infection (at least $50 \%$ of cells within the target tissue present enlarged nuclei) by "++", and severe infection (over $80 \%$ of the cells within the target tissue present enlarged nuclei) by "+++". Tissues that were not able to be sectioned are marked "NS". 
A

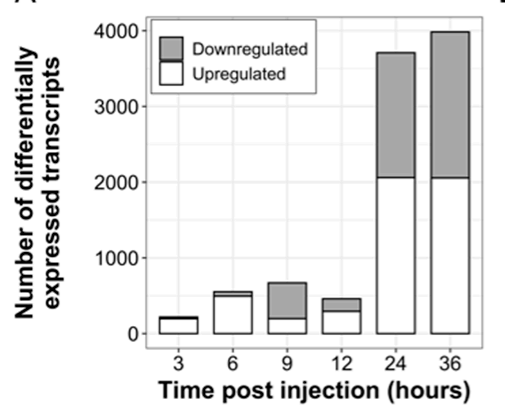

B

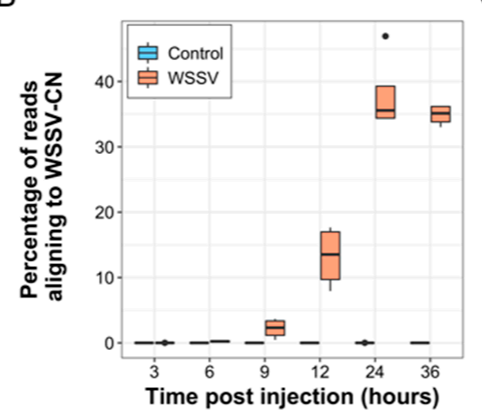

C

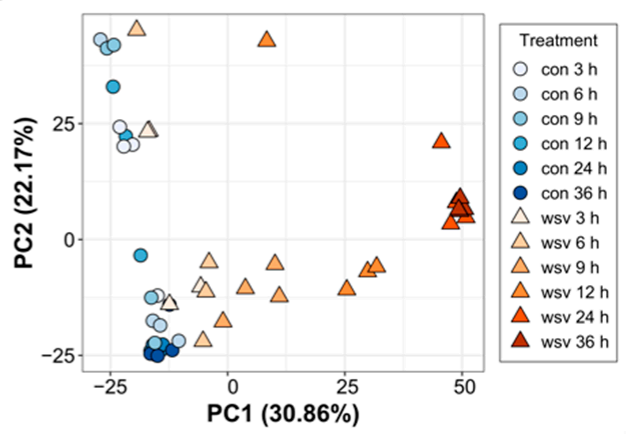

D

E
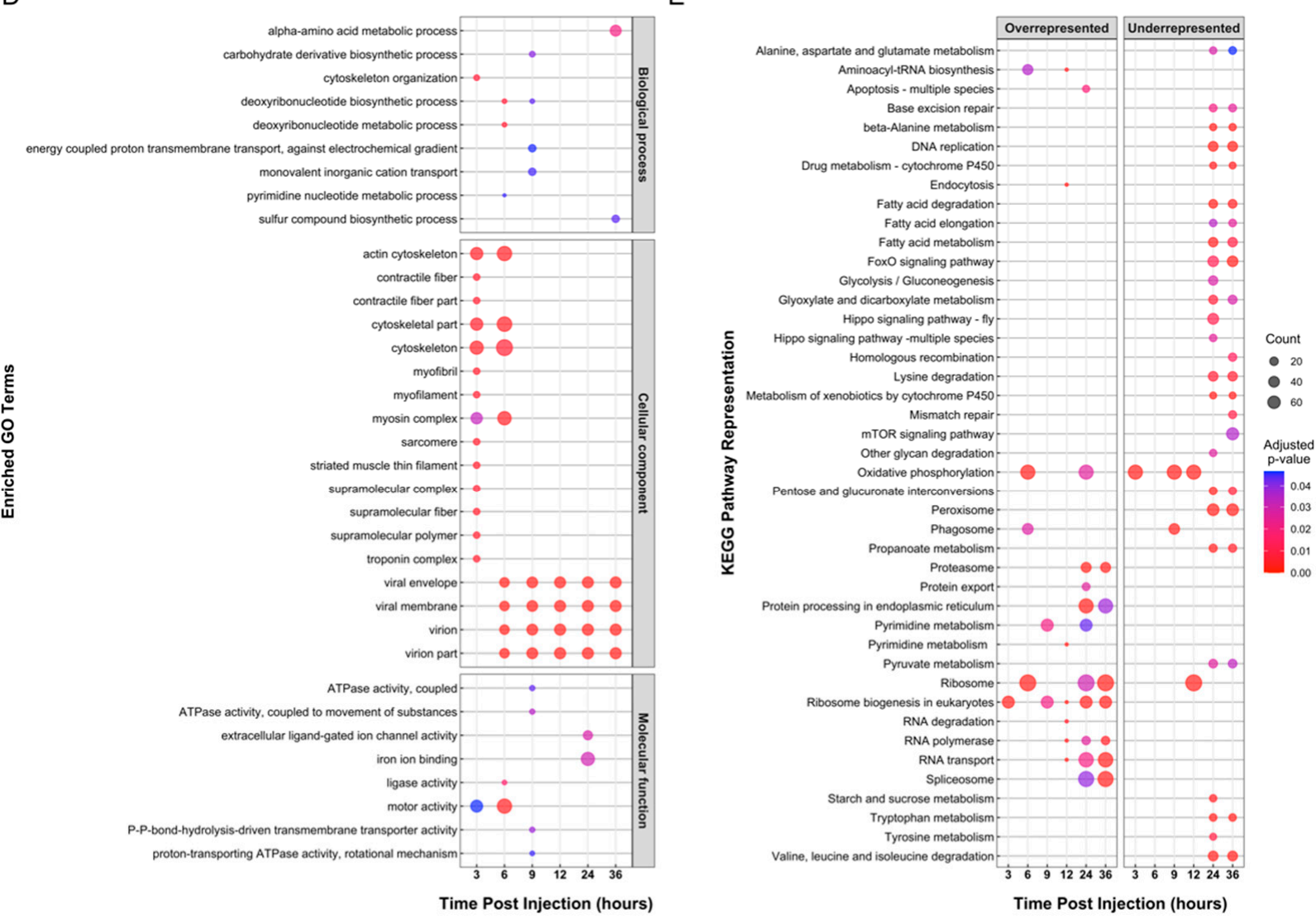

Figure 3. Transcriptome analysis. (A) A stacked bar plot depicting the number of significantly upregulated and downregulated transcripts over time following WSSV injection. (B) Boxplot illustrating the percentage of trimmed sequencing reads from control and WSSV-injected shrimp aligning to the WSSV-CN genome (GenBank Accession: AF332093.3 [61]) over time. (C) Principal component analysis demonstrating similarity between the differentially expressed transcripts in each treatment and timepoint according to principal component 1 (PC1) and principal component 2 (PC2). (D) Temporal enrichment of gene ontology (GO) terms within the lists of differentially expressed transcripts at each timepoint following WSSV injection. The size of each point indicates the number of transcripts assigned to each GO term, and the colour indicates the adjusted $p$-value associated with the GO term's enrichment. (E) Over- and underrepresented KEGG pathways within the expressed transcripts at each timepoint following WSSV injection. Point size indicates the number of transcripts present within each KEGG pathway, and the colour indicates the adjusted $p$-value associated with the KEGG pathway's enrichment.

\section{4. miRNA Sequencing, Prediction and Analysis}

A total of 120,409,899 small RNA sequencing reads were obtained. Quality trimming and filtering resulted in retention of $33.9 \%$ of the total reads $(40,773,190)$, averaging 849,441 $( \pm 65,170)$ reads per sample, for downstream analyses. Condensation of these reads revealed 1,976,755 unique sequences across the 48 samples, with an average of $44,182( \pm 3309)$ 
unique sequences per sample. In addition, 655,964 alignments to the shrimp genome were reported for prediction of 296 reduced-redundancy P. vannamei miRNAs using the miRDeep2 pipeline (Dataset S7). Sixty-three (21.3\%) were assigned annotations and $233(78.7 \%)$ were considered novel. Differential expression analysis revealed 27 WSSV-responsive shrimp miRNAs that were significantly differentially expressed in at least one timepoint following injection (Table S1). Similar to the transcriptome, the number of significantly differentially expressed miRNAs followed a biphasic expression pattern, with limited differential expression in the very early stages $(\leq 6)$ compared to later stages of infection $(\geq 13)$ (Figure $4 \mathrm{~A}, \mathrm{~B})$. In addition, most of the differentially expressed miRNAs were upregulated $(22,81.5 \%)$ in response to WSSV injection.

\subsection{Functional Analysis of Transcriptome and miRNA Data}

Functional analysis of differentially expressed transcripts identified 35 significantly enriched GO terms $(p<0.05)$ (Figure 3D) and 43 significantly over- or underrepresented KEGG pathways ( $p<0.05$ ) (Figure 3E) throughout the infection process-these are listed in Tables S2 and S3. At each timepoint, distinct processes were altered in response to WSSV infection. Among the differentially expressed miRNAs, 1729 unique target transcripts were predicted in the transcriptome (Dataset S8), and across all miRNA target lists 480 GO terms were enriched, indicating a broad array of processes that may be regulated by the WSSV-responsive miRNAs detected.

\subsubsection{Cytoskeleton Remodelling Assists Early WSSV Entry and Movement}

From 3-6 hpi, the most significantly enriched terms were associated with components of the cytoskeleton and the process of cytoskeleton organization (Figure 3D). The contributing transcripts included both cytoskeletal building blocks (e.g., Actin-57B (3 hpi: $\left.\log \mathrm{FC}=9.43, \mathrm{FDR}=3.01 \times 10^{-3}, 6 \mathrm{hpi}: \log \mathrm{FC}=11.20, \mathrm{FDR}=2.65 \times 10^{-3}\right)$ and Actin-1-like (3 hpi: $\left.\log \mathrm{FC} 10.24, \mathrm{FDR}=7.20 \times 10^{-6}, 6 \mathrm{hpi}: \log \mathrm{FC}=10.54, \mathrm{FDR}=5.50 \times 10^{-5}\right)$ ) and components of the molecular motors that enable intracellular movement (e.g., 9 myosin heavy chain isoforms including myosin heavy chain, and muscle-like isoforms X2 (3 hpi: $\left.\log \mathrm{FC}=11.72, \mathrm{FDR}=4.80 \times 10^{-5}, 6 \mathrm{hpi}: \log \mathrm{FC}=9.62, \mathrm{FDR}=1.97 \times 10^{-4}\right)$ and $\mathrm{X} 8(3 \mathrm{hpi}:$ $\left.\log \mathrm{FC}=10.36, \mathrm{FDR}=2.74 \times 10^{-6}, 6 \mathrm{hpi}: \log \mathrm{FC}=13.00, \mathrm{FDR}=2.26 \times 10^{-5}\right)$ ), which were significantly upregulated in response to WSSV injection.

Concomitantly, novel miRNAs Pva-pmiR-120 (3hpi: $\log F C=22.65$, FDR $=3.45 \times 10^{-7}$ ) and Pva-miR-novel_11 (6hpi: $\log F C=0.98$, FDR $=0.02)$ (Figure 4C), with lengths of 19 and $22 \mathrm{nt}$, randfold (1.6 and 1.6) and minimum free energy (MFE) (2.2 and 2.1) values supporting their validity as true miRNAs, were significantly upregulated (Figure 4D). For each of these, many mRNA targets were predicted (141 and 201, respectively). The biological function of Pva-pmiR-120 may be inferred by the enrichment of terms in the target transcript list for the regulation of microtubule polymerisation or depolymerisation $\left(\right.$ FDR $\left.=7.74 \times 10^{-4}\right)$ and calcium-dependent cysteine-type endopeptidase activity $\left(\mathrm{FDR}=2.80 \times 10^{-3}\right)$. This is further supported by the fact that this miRNA is predicted to target the transcripts tubulin-specific chaperone cofactor E-like protein (required for correct organisation of microtubule cytoskeleton) and calpain C-like isoforms (involved in breakdown of cytoskeletal proteins and cytoskeletal remodelling), respectively (Figure 4D). In addition, Pva-miR-novel_11 was predicted to target myosin-11-like isoform X2 among other cytoskeletal transcripts, suggesting a role for these miRNAs in cytoskeletal remodelling during early WSSV infection. These hypotheses are based on bioinformatics predictions and require further validation work to demonstrate the biological significance of these predicted interactions. 
A

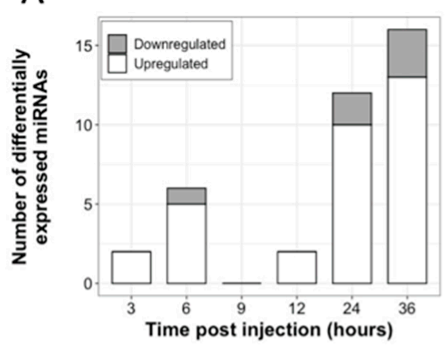

C

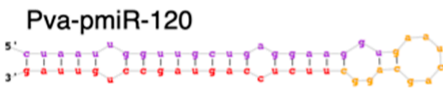

Pva-miR-novel_11

3.

Pva-miR-133

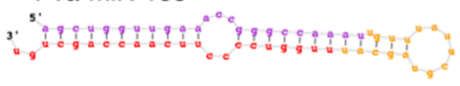

Pva-miR-1

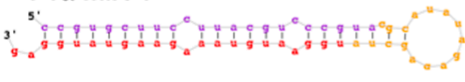

Pva-pmiR-31

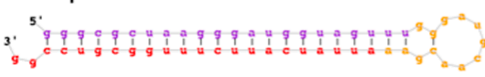

Pva-pmiR-44

3.

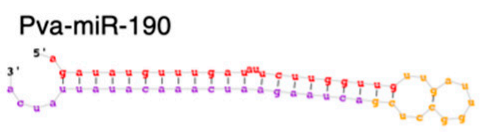

Pva-pmiR-118

3. "9.

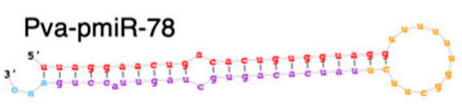

B

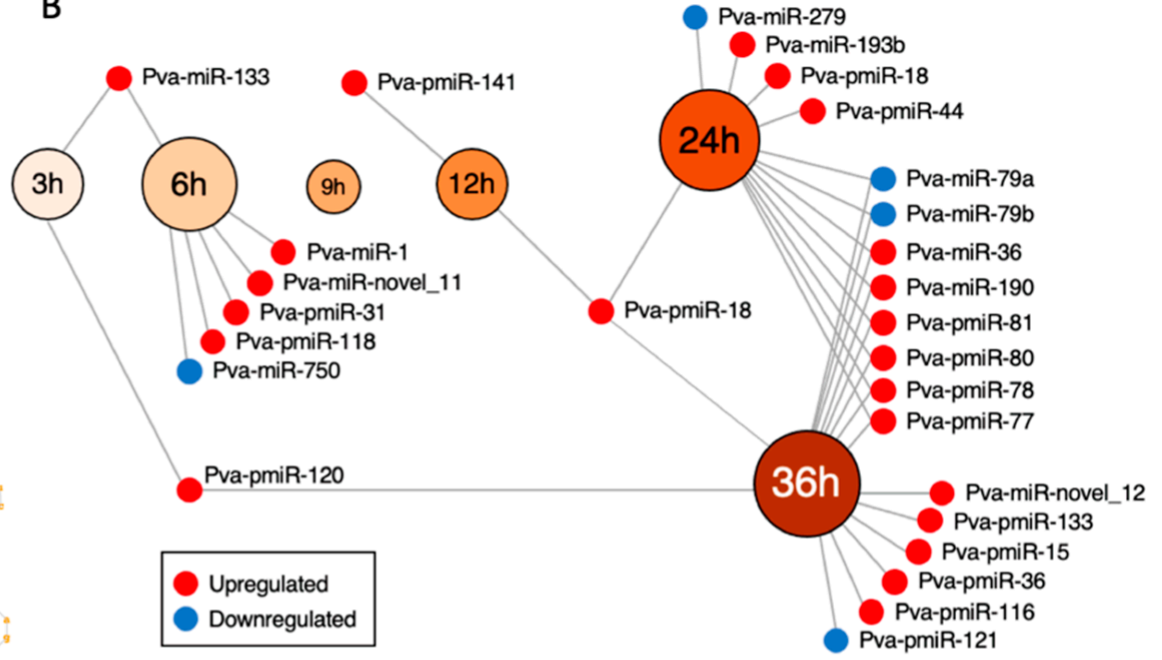

\section{D}
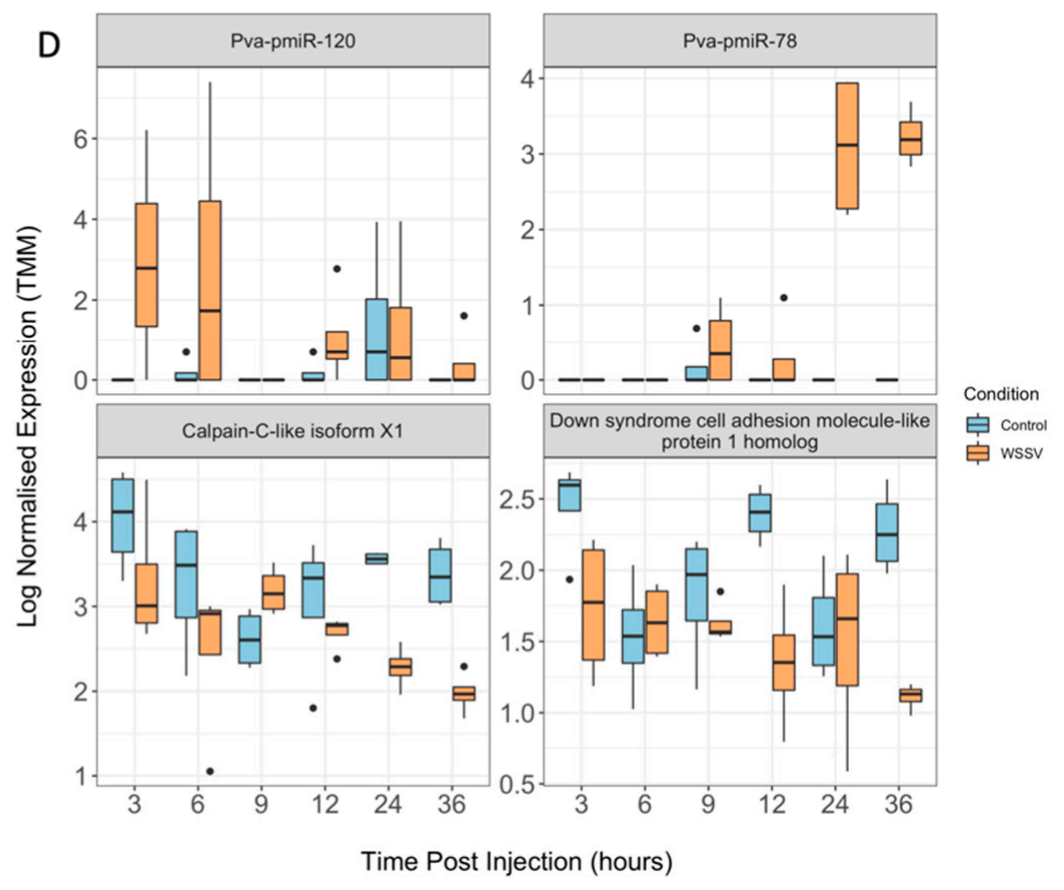

Figure 4. miRNA-seq results. (A) Stacked bar plot displaying the number of significantly differentially expressed miRNAs at each timepoint following WSSV injection. (B) Venn diagram depicting the overlap in differentially expressed miRNAs between the timepoints sampled following WSSV injection. (C) RNAfold structure of the miRNAs discussed herein. Red nucleotides depict the mature miRNA sequence, yellow nucleotides correspond to the characteristic hairpin loop of miRNA precursors and purple nucleotides depict the star miRNA sequence. (D) Boxplots displaying the temporal transcription patterns of novel shrimp miRNA Pva-pmiR-120, which is significantly upregulated at $3 \mathrm{hpi}$, and its predicted target calpain-C-like isoform X1, which is subsequently downregulated. In addition, a boxplot of novel shrimp miRNA Pva-pmiR-78, which is significantly upregulated at 24 and $36 \mathrm{hpi}$, and its predicted target down syndrome cell adhesion molecular-like protein 1 homolog, which is concomitantly downregulated.

\subsubsection{Pathogen-Associated Phagocytic Activity Is Altered during Early Infection}

Two previously described miRNAs, Pva-miR-133 ( 3 hpi: $\log F C=6.41, F D R=2.17 \times 10^{-3}$, 6 hpi: $\left.\operatorname{logFC}=8.00, \mathrm{FDR}=1.76 \times 10^{-5}\right)$ and Pva-miR-1 $\left(6\right.$ hpi: $\left.\operatorname{logFC}=2.70, \mathrm{FDR}=1.43 \times 10^{-3}\right)$ (Figure 4C) were upregulated during early infection. Pva-miR-133 was predicted to interact 
with 167 transcripts that were enriched for GO terms SWI/SNF complex $\left(\mathrm{FDR}=5.26 \times 10^{-3}\right)$ and ATP-dependent chromatin remodelling $\left(\mathrm{FDR}=3.42 \times 10^{-2}\right)$. The SWI/SNF-related matrix-associated actin-dependent regulator of chromatin subfamily E member 1-like isoform $\mathrm{X} 2$ which contributed to this enrichment, was downregulated at $9 \mathrm{hpi}(\log \mathrm{FC}=-4.27$, $p=4.63 \times 10^{-2}$ ), and plays a fundamental role in the regulation of phagocytosis, chromatin remodelling and transcriptional regulation [80,81]. Pva-miR-1 target, the regulator of G-protein signalling 9 isoform X2, which plays a functional role in the regulation of Ras and Rho signal transduction, may also regulate phagocytosis during early WSSV infection. This is further supported by the significant overrepresentation of the phagosome pathway (KEGG ID: dme04145) at $6 \mathrm{hpi}(\mathrm{FDR}=0.03)$ and subsequent underrepresentation at $9 \mathrm{hpi}$ $\left(\mathrm{FDR}=2.15 \times 10^{-4}\right)$.

\subsubsection{WSSV Replication First Detected at 6 hpi}

The enrichment of the deoxyribonucleotide metabolic process and deoxyribonucleotide biosynthetic process terms at $6 \mathrm{hpi}$ indicated an increase in DNA replication (Figure 3D). This coincided with the upregulation of virus-derived transcripts such as thymidylate synthetase (WSV067) $(\log \mathrm{CPM}=4.74)$, TK-TMK chimeric thymidine and thymidylate kinase (WSV395) $(\log C P M=3.98)$, and viral DNA polymerase (WSV514) $(\log C P M=4.40)$, which provide considerable independence from the host's nucleotide metabolism machinery. These transcripts also contributed to the significant enrichment of virus-associated GO terms virion part, virion, viral envelope, and viral membrane (FDR < 0.01) during this timepoint. Host transcription-associated mediator of RNA polymerase II transcription subunit 15-like was significantly upregulated $(\log \mathrm{FC}=10.10$, $\mathrm{FDR}=1.20 \times 10^{-5}$ ) and the ribosome KEGG pathway overrepresented (Figure $3 \mathrm{E}$ ) at $6 \mathrm{hpi}$, suggesting an accompanying increase in protein biosynthesis at this timepoint.

3.5.4. Metabolic Shifts Associated with a White Spot-Induced Warburg Effect Are Likely Driven by Novel WSSV-Responsive miRNAs

Novel shrimp miRNAs Pva-pmiR-31 and Pva-miR-novel-11, which were significantly upregulated at $6 \mathrm{hpi}\left(\log \mathrm{FC}=1.74, \mathrm{FDR}=1.71 \times 10^{-4}\right.$ and $\log \mathrm{FC}=0.98, \mathrm{FDR}=0.02$, respectively), were predicted to target 6 and $201 \mathrm{mRNAs}$, respectively. These lists of mRNA targets were enriched for metabolism-associated GO terms such as 2,6-bisphosphate metabolic process $\left(\mathrm{FDR}=6.55 \times 10^{-3}\right)$ and phosphopyruvate hydratase activity $\left(\mathrm{FDR}=5.19 \times 10^{-10}\right)$. The mRNAs contributing to these terms included enzymes such as 6-phosphofructo-2kinase/fructose-2,6-bisphosphatase and enolase isoforms $\mathrm{X} 1$ and $\mathrm{X} 2$, which play a role in determining the rates of glycolysis and may play a role in establishing the Warburg-like effect associated with metabolic changes in response to WSSV infection [82,83].

\subsubsection{ATP-Dependent Proton Transporter Downregulation May Disrupt Lysosome Formation at $9 \mathrm{hpi}$}

As infection progressed, terms associated with PP-bond-hydrolysis-driven transmembrane transporter activity and ATPase activity, coupled with transmembrane movement of substances, were enriched (Figure 3D). This enrichment was associated with a significant downregulation of 12 V-type ATPase subunits, including the $16 \mathrm{kDa}$ proteolipid subunit $\left(\log \mathrm{FC}=-5.36, \mathrm{FDR}=1.16 \times 10^{-3}\right)$ and subunits $\mathrm{C}-$, $\mathrm{D}-$, and E-like $\left(\log \mathrm{FC}=-3.65, \mathrm{FDR}=2.22 \times 10^{-4}, \log \mathrm{FC}=-3.53, \mathrm{FDR}=6.03 \times 10^{-4}, \log \mathrm{FC}=-3.24\right.$, FDR $=-1.85 \times 10^{-3}$, respectively). These membrane-embedded ATPases are associated with vesicle acidification, therefore their downregulation has the potential to subvert lysosome formation to benefit either WSSV or the host. This also has a significant impact on the phagosome pathway, which was significantly underrepresented at 9 hpi (Figure 3E).

\subsubsection{Oxidoreductase Activity Was Strongly Perturbed at 24 hpi in WSSV-Infected Shrimp}

At $24 \mathrm{hpi}$, significant alterations to the transcription of electron transport chain components may associate with oxidative stress, explaining the mechanism by which WSSV infection causes cell death and mortality. This was supported by the enrichment of oxi- 
doreductase activity terms (acting on paired donors, with incorporation or reduction of molecular oxygen, and acting on $\mathrm{CH}-\mathrm{NH}$ groups of donors, NAD or NADP as acceptor (Figure 3D)), and also by the overrepresentation of the oxidative phosphorylation KEGG pathway at 24 hpi (Figure 3E). Overlaying the expression data on this KEGG pathway (Figure S3) demonstrated temporal shifts throughout the experiment. Notably, at 24 hpi complexes I-IV of the electron transport chain were upregulated, whereas complex V transcripts were downregulated blocking the final step of electron transport and ATP synthesis. The resulting uncoupling of the electron transport chain can lead to a process known as "uncoupling to survive" [84], which increases reactive oxygen species production and, at low levels, can boost innate immune function [85]. However, it also has the potential to lead to mitochondrial membrane permeabilisation and trigger the apoptotic pathway, which was also overrepresented at $24 \mathrm{hpi}$ (Figure 3E). Collectively, these oxidoreductase alterations could form a mechanism of rapid onset of mortality in WSSV-infected shrimp by inducing apoptosis. This is further supported by the upregulation of novel miRNA Pva-pmiR-44 at $24 \mathrm{hpi}\left(\log \mathrm{FC}=1.09, \mathrm{FDR}=5.00 \times 10^{-2}\right)($ Figure $4 \mathrm{C})$, which may negatively regulate the translation of its target mRNA hormone receptor 4, resulting in increased apoptosis [86]. The concomitant significant upregulation of known miRNA Pva-miR-190 (Figure 4C) at 24 and 36 hpi $\left(\operatorname{logFC}=1.20, \mathrm{FDR}=2.03 \times 10^{-3}\right.$ and $\operatorname{logFC}=1.73, \mathrm{FDR}=3.44 \times 10^{-7}$, respectively), which has previously been associated with the activation of apoptosis and positive regulation of phagocytic activity, also supports this hypothesis [24].

\subsubsection{Late Infection Highlights Novel WSSV-Induced Transcript and miRNA Alterations}

During the later stages of WSSV infection (24 hpi onwards) several distinct processes, some of which have not previously been reported, were altered in response to WSSV injection. This included enrichment of the iron ion binding term (24 hpi) (Figure 3D), novel downregulation of glutamate and acetylcholine receptors at $24 \mathrm{hpi}$, and alterations at $36 \mathrm{hpi}$ to methylation-associated transcripts such as methionine synthase-like $(\log \mathrm{FC}=3.58$, $\left.\mathrm{FDR}=2.35 \times 10^{-18}\right)$ and betaine-homocysteine S-methyltransferase 1-like $(\operatorname{logFC}=-7.43$, $\mathrm{FDR}=7.89 \times 10^{-7}$ ). However, the ability to interpret the impact of these changes on the late infection process is compounded by the high probability that many of the transcriptional changes at this stage are associated with shrimp that are succumbing to advanced disease.

During the WSSV infection process, few immune transcripts were differentially expressed, resulting in no enrichment of immune-related GO terms, suggesting that the immune responses mounted by whiteleg shrimp may be insufficient to prevent progression of WSSV infection to disease in this host. Whilst novel upregulated miRNAs that are predicted to target WSSV transcripts, (such as Pva-pmiR-118 (12 h; $\log F C=2.20$, FDR $\left.=3.66 \times 10^{-2}\right)$ (Figure 4C)—predicted to target WSSV transcript Swssvgp111), may modulate WSSV transcription to defend against infection, long-term adaptive-like immune memory may be impaired, thereby counteracting these subtle effects. For example, novel shrimp miRNA Pva-pmiR-78 expression was significantly increased at $24 \mathrm{hpi}(\log \mathrm{FC}=7.85$, $\mathrm{FDR}=8.07 \times 10^{-4}$ ) and coincided with a significant decrease in expression of its target transcript down syndrome cell adhesion molecule (Dscam)-like protein 1 homolog at $36 \mathrm{hpi}$ $\left(\log \mathrm{FC}=-2.10, \mathrm{FDR}=5.82 \times 10^{-7}\right)($ Figure $4 \mathrm{C}, \mathrm{D})$. Dscam has been linked with pathogen recognition and playing an essential role in arthropod immunity [87], including WSSV defence and survival [88].

\section{Discussion}

We investigated transcriptional responses to WSSV in the major farmed shrimp $P$. vannamei in order to establish a detailed molecular understanding of the earliest stages of WSSV infection. WSSV injection resulted in rapid temporal transcriptional (mRNA and miRNA) changes, corresponding to the various stages of infection over time. We provide the first detailed overview of the molecular mechanisms of WSSV infection and P. vannamei response during early infection (from 3-12 hpi), which are summarised in Figure 5. We identify novel processes associated with WSSV infection (including the upregulation of 
cytoskeletal components from 3-6 hpi, novel host miRNAs regulating metabolism at $6 \mathrm{hpi}$, disruption of vesicle acidification and cellular recycling at $9 \mathrm{hpi}$, and a WSSV-responsive novel host miRNA that targets an immune priming transcript at $24 \mathrm{hpi}$ ) that could be further explored for the development of WSSV prophylactics and therapeutics.

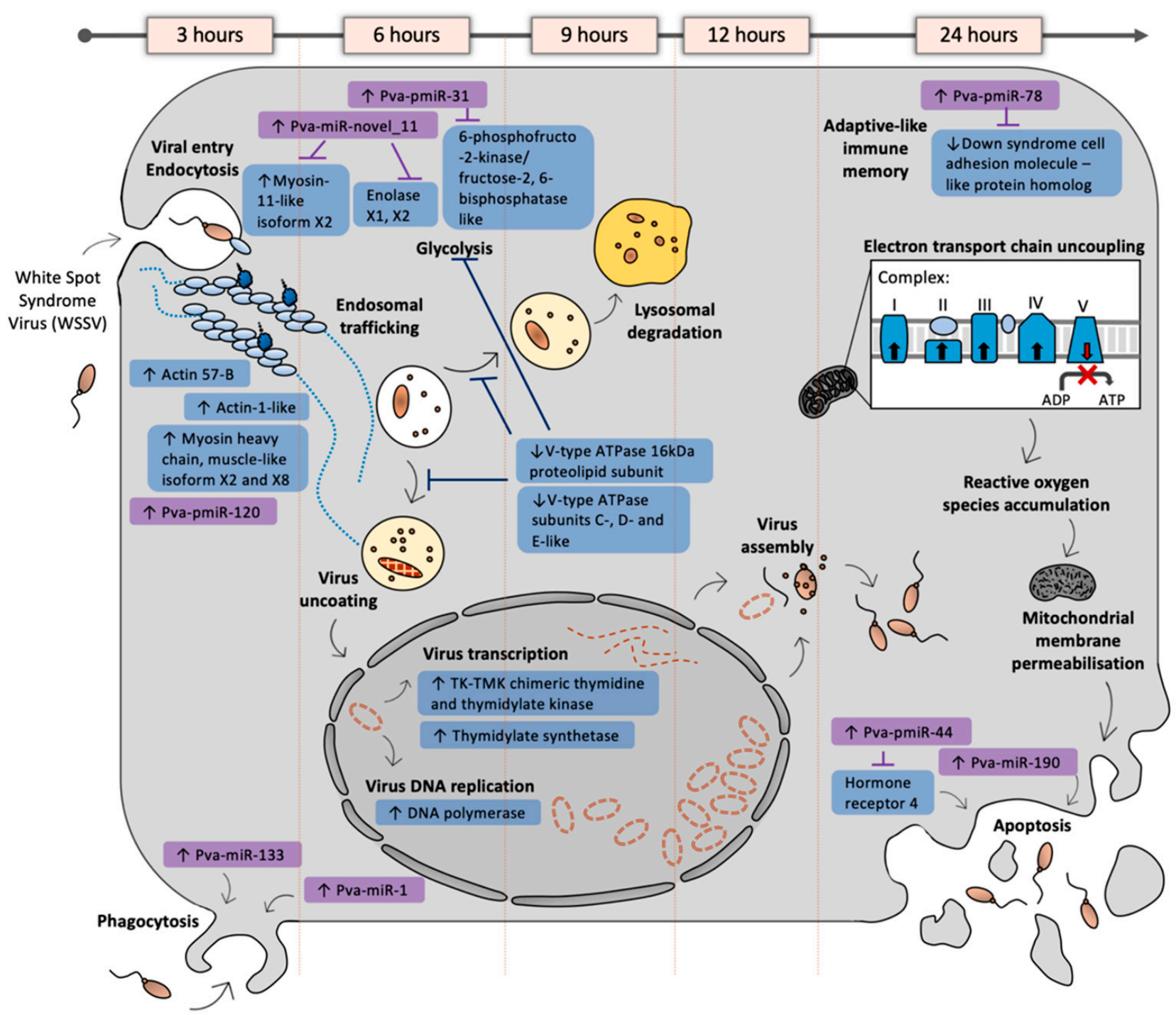

Figure 5. Diagram representing the transcriptome changes documented in P. vannamei over time following WSSV injection. Key mRNAs are represented in blue boxes and miRNAs in purple boxes, black text indicates the key processes that are altered during WSSV infection. mRNAs and miRNAs that were significantly upregulated or downregulated are marked with upward and downward pointing arrows respectively.

4.1. Temporal Dynamics in Transcriptional Responses to WSSV Infection Illustrate Mechanisms of Viral Entry and Replication during Early Infection, and Host Responses during the Late Infection Stages

Interrogation of the transcriptome highlighted the involvement of host cytoskeletal machinery to aid WSSV entry from 3 hpi. WSSV entry occurs via multiple endocytic routes [89-91], each requiring adaptations to the cytoskeleton structure for successful infection. To this end, the significant upregulation of actins may enhance WSSV entry as actin coimmunoprecipitates with VP26 and is thus a probable receptor for WSSV [92]. Following entry, actin upregulation also leads to the formation of stress fibres, providing additional molecular highways for the trafficking of the virus, similar to ebolavirus [93], 
and promoting phagocytosis, which may further aid entry and movement throughout the densely packed intracellular environment. The significant upregulation in myosin described here, also previously reported in the proteomes of WSSV-infected shrimp and crabs $[94,95]$ indicates an increase in ATP-dependent molecular motors, which, when bound to actin, regulate movement within the cell [96]. However, contrary to its proposed involvement in shrimp immunity [97,98], as myosins are important factors related to growth performance [18], its hypothesised role in WSSV entry and trafficking may explain the high level of WSD susceptibility of $P$. vannamei that have been selectively bred for fast growth [99]. During late WSSV infection (48-96 hpi), a contrasting decrease in actins and myosins was reported in the hepatopancreas [100], which may also explain tissue-specific differences in susceptibility as the gills are a main target for WSSV infection. From 6 hpi, enhanced cytoskeletal processes were coupled with the upregulation of WSSV transcripts, such as WSSV thymidylate synthetase, that may offer the virus independence from host transcriptional machinery, and the enrichment of DNA-replication associated GO terms, such as deoxyribonucleotide biosynthetic process, are in line with prior literature stating viral replication begins at $6 \mathrm{hpi}$ [101].

We report for the first time the involvement of 12 V-type ATPase subunits in the WSSV infection process as early infection progresses $(9 \mathrm{hpi})$. V-type ATPases have been implicated as important mediators of the infection process of many viral infections including human Cytomegalovirus where they facilitate virion assembly [102] and during Influenza A virus where decreased glucose levels result in disassembly of V-ATPases, inhibition of glycolysis and Influenza A suppression [103]. Their role during WSSV infection is not presently clear, but subversion of lysosome formation could either aid or hinder the virus life cycle by protecting it from degradation in the lysosome or benefiting the host by limiting available acidic environments required by WSSV for uncoating [90]. As this response occurs following WSSV translation and replication initiation it is likely to have a limited protective effect and could indicate a response by the host to limit glycolysis, which is induced during infection [83].

In the later 'early' timepoints sampled (12 hpi) and at the start of 'late' infection (24 hpi), a shift to increased transcription occurred, coinciding with the appearance of WSD pathognomonic signs in some shrimp and the onset of mortality. In late infection (from $24 \mathrm{hpi}$ ) as shrimp succumbed to WSD, significant disruption to the electron transport chain was observed as components of the complexes I-IV were significantly upregulated and those of complex V, the ATPase complex, were significantly downregulated, inhibiting ATP synthesis. We hypothesise that increased reactive oxygen species were likely produced due to the high proton motive force generated, which can enhance invertebrate immunity at low levels [85]. This has previously been observed transiently from $30 \mathrm{~min}$ to $2 \mathrm{~h}$ following WSSV injection, following which WSSV displays an unusual ability to neutralise the host's ROS defences until 24 hpi [104]. However, increased oxidative stress at 24 hpi may also lead to mitochondrial permeabilisation and initiation of apoptotic cascades [105] intended to protect the host, but instead triggering the release of newly assembled WSSV. Alterations to mitochondrial bioenergetics typically favours virus production [106]. The disappearance of mitochondrial cristae in WSSV-infected red claw crayfish gills [107] supports the hypothesis that these responses likely occur in response to WSSV infection stress as a last resort to enhance survival, but instead aid WSSV release.

\section{2. miRNA Responses to WSSV Infection Suggest Dysregulation of Phagocytosis, Cellular Respiration and Host Immunity}

Typically, increased miRNA transcription equates to posttranscriptional silencing of target mRNAs, although exceptions exist and the extent of silencing can range from fine-tuning to complete repression [108]. The significant upregulation of shrimp miRNAs reported here therefore suggests a suppressive effect of WSSV-responsive miRNAs on host transcriptional responses. During early infection, miRNAs Pva-miR-133 and PvamiR-1 were hypothesised to have opposing effects on phagocytic activity. The former was also upregulated in sea cucumber Apostichopus japonicus in response to Vibrio splendidus 
causing significant increases in phagocytic activity [109], whilst the latter, a known WSSVresponsive miRNA [70] has a confirmed negative regulatory role in phagocytosis [110]. The differential regulation of phagocytic activity during the critical timepoints where virus entry occurs may indicate that this pathway is being utilised by WSSV to reach the nucleus or that the process of pathogen removal is being altered by the host to suppress WSSV infection.

Many of the identified miRNAs were not significantly homologous to known model invertebrate miRNAs and require classification in future studies. This includes novel miRNAs Pva-pmiR-31 and Pva-miR-novel-11 whose negative regulation of glycolytic enzymes during early WSSV infection (6 hpi) coincides with Warburg-like metabolic shifts in WSSV-infected hosts [82,83] suggesting their involvement in either the effectors or suppressors of metabolic hijack by WSSV. During late infection, the ability of novel miRNA Pva-pmiR-78 to negatively regulate the translation of a Dscam-like homology provided the first suggestion that WSSV may be able to alter longer-term immune memory in WSSV-infected shrimp, in addition to shorter-term immune adaptations that enable its propagation. Dscam, a hypervariable protein that can be alternatively spliced to function as a pathogen recognition molecule for immune priming in Crustacea [111], is predicted to encode a possible 8970 unique isoforms in P. vannamei [112]. Knockdown of Dscam by siRNA was previously shown to decrease host survival following WSSV infection [88] and it is hypothesised that persistent WSSV exposure results in "clouds" of Dscam isoforms to defend against reinfection [112,113]. Its significant downregulation reported here, possibly because of Pva-pmiR-78 upregulation, may prevent the ability of the host to recognise WSSV in subsequent infections, increasing $P$. vannamei susceptibility to WSD.

\subsection{Limitations}

Despite the wealth of novel host-pathogen interactions described herein, the information gleaned from transcriptional studies of non-model organisms such as P. vannamei is still limited due to the quality of the annotations available for incomplete genomic resources. Interpretations rely heavily on the assignment of correct annotations to transcripts and miRNAs based on sequence similarity to distant species, and are underpinned by the assumption that function is evolutionarily conserved. To counteract against this, in this study we employed a number of strategies designed to improve annotations while minimising false positives, including: assigning lower thresholds for annotation, screening sequences for conserved motifs, and using complete non-redundant protein databases to query sequences. In addition, whilst miRNA target prediction typically results in long lists of candidate mRNA targets, which can be informative to identify the most likely processes affected by the regulation of those miRNAs, these lists are likely to include a large number of false positive interactions. To minimise the reporting of false positive predictions of miRNA-mRNA interactions, a combination of prediction tools was applied as recommended best practice [114]. Conservative parameters such as strict alignment in the seed region and a low minimum free energy score cut-off [115] were incorporated to further reduce this effect. Despite this, we acknowledge that the possibility of false positives (as well as false negatives) exists and that the data we present constitute hypotheses for the functionality of the interactions predicted to occur, with further experimental validation required in order to validate the proposed interactions and their biological significance.

\section{Conclusions}

We addressed a significant gap in our understanding of the early responses of susceptible P. vannamei to WSSV infection through integration of both transcript and miRNA expression data. Our findings identified key molecular pathways potentially involved in the initiation of the infection including the upregulation of cytoskeletal transcripts associated with viral trafficking during the initial stages of infection followed by metabolic shifts towards glycolysis, likely coordinated via miRNA-mediated post-transcriptional regulation. This was in contrast with that observed during late infection stages (after $24 \mathrm{hpi}$ ), where 
putative mitochondrial uncoupling-induced cell death was observed. Importantly we report for the first time that during late infection the novel shrimp miRNA, Pva-pmiR-78, was induced, and this was associated with a suppression in DScam transcription, a gene involved with immune memory in crustaceans. In this manner, we propose that WSSV may cause a miRNA-induced downregulation of core elements of the immune system in shrimp, contributing to its high susceptibility to WSSV infection. Together, our findings provide novel insights on how the virus maintains unrivalled access to DNA synthesis and regulation, and metabolites to ensure successful viral entry, replication, and release, including how it might avoid the immune response of the host. Our study therefore opens new avenues to develop treatment and preventative strategies to combat WSD.

Supplementary Materials: The following are available online at https:/ / www.mdpi.com/article/10 .3390/v13061140/s1, Figure S1: RNA-seq bioinformatics pipeline; Figure S2: miRNA-seq bioinformatics pipeline; Figure S3: Oxidative phosphorylation pathway transcript expression in response to WSSV injection over time; Table S1: Significantly differentially expressed miRNAs in response to WSSV injection over time; Table S2: Gene ontology enrichment among significantly differentially expressed transcripts; Table S3: KEGG pathway representation; Dataset S1: Differentially expressed transcripts at $3 \mathrm{hpi}$; Dataset S2: Differentially expressed transcripts at $6 \mathrm{hpi}$; Dataset S3: Differentially expressed transcripts at 9 hpi; Dataset S4: Differentially expressed transcripts at 12 hpi; Dataset S5: Differentially expressed transcripts at $24 \mathrm{hpi}$; Dataset S6: Differentially expressed transcripts at $36 \mathrm{hpi}$; Dataset S7: Complete list of reduced-redundancy P. vannamei miRNAs; Dataset S8: Table of predicted mRNA targets for significantly differentially expressed miRNAs.

Author Contributions: Conceptualization, R.S.M., K.S.B., E.M.S., R.v.A., C.R.T. and G.D.S.; methodology, R.S.M., K.S.B., L.K.B., G.D.S., E.M.S., C.R.T. and R.v.A.; formal analysis, R.S.M. and R.v.A.; investigation, R.S.M., K.S.B., S.H.R., D.M., A.F. and K.M.; data curation, R.S.M. and R.v.A.; writingoriginal draft preparation, R.S.M. and L.K.B.; writing-review and editing, R.S.M., L.K.B., K.S.B., A.F., D.M., K.M., S.H.R., G.D.S., C.R.T., R.v.A. and E.M.S.; visualization, R.S.M.; supervision, E.M.S., R.v.A. and C.R.T.; funding acquisition, E.M.S., R.v.A., C.R.T., G.D.S., K.M., A.F. All authors have read and agreed to the published version of the manuscript.

Funding: This research was jointly funded by the University of Exeter's Open Innovation Platform and Centre for Environment Fisheries and Aquaculture Science (Cefas) Seedcorn Contract (DP318) (Building a molecular platform for understanding the host-pathogen interface in invertebrates) (to G.D.S., E.M.S., R.v.A. and C.R.T.). This project utilised equipment funded by the Wellcome Trust Institutional Strategic Support Fund (WT097835MF), Wellcome Trust Multi User Equipment Award (WT101650MA) and BBSRC LOLA award (BB/K003240/1).

Institutional Review Board Statement: The use of animals within this study was reviewed and approved by the internal ethics board at the Centre for Environment Fisheries and Aquaculture Science.

Informed Consent Statement: Not applicable.

Data Availability Statement: The data for this project are deposited within BioProject PRJNA716175. The raw sequence data (RNA-seq and microRNA-seq) are deposited within the Sequence Read Archive (accessions: SRR14027651-SRR14027746) and the de novo assembled transcriptome is deposited in figshare (https:/ / doi.org/10.6084/m9.figshare.14410313.v1 (accessed on 1 May 2021)).

Acknowledgments: RSM acknowledges the support provided by Caroline Daumich in histological processing and the Experimental Facility staff at Cefas, Sally Latham, Michaela Bonar, Ellen Blaker and Chris Baker.

Conflicts of Interest: The authors declare no conflict of interest. The funders had no role in the design of the study; in the collection, analyses, or interpretation of data; in the writing of the manuscript, or in the decision to publish the results. 


\section{Appendix A}

Appendix A.1. WSSV miRNA Analysis and Results

Appendix A.1.1. WSSV miRNA Analysis

Viral miRNAs were predicted following the same protocol as host miRNAs, using the WSSV-CN reference genome (Genbank Accession: AF332093.3 [61]) for mapping and prediction. Known mature WSSV miRNAs downloaded from VIRmiRNA v1.0 database (July 2019, [116]) were used as a reference dataset to guide predictions. All miRNA sequences were also subjected to NCBI BlastN v2.6.0+ BlastN-Short [71]) search against all WSSV miRNAs within the VIRmiRNA v1.0 database (July 2019, [116]) with an e-value cut-off score of $1 \times 10^{-5}$, which was chosen to allow for the short length of these sequences and expected $100 \%$ similarity score.

The breadth of coverage of small RNA (sRNA) sequences across the WSSV genome (GenBank Accession: AF332093 [61]) was assessed using Bowtie2 v2.2.9 [62]. Samtools v1.4 [64] was used to sort and convert alignments to bam files for assessment of depth and breadth of coverage. Coverage was also visually inspected using the Integrative Genomics Viewer v2.4.17 [117].

\section{Appendix A.1.2. WSSV miRNA Results}

The prediction methods applied within the present study did not identify any candidate WSSV-derived miRNAs. Similarity searches of collapsed sRNA reads against 40 previously classified WSSV miRNAs within the VIRmiRNA database [116] also returned no significant hits. Given the clear exponential increase in viral mRNA transcription observed in the RNA-seq dataset, it is unusual that no WSSV-derived miRNAs were identified within the data. WSSV miRNA expression patterns have been reported in previous studies $[118,119]$, therefore, viral miRNAs were expected to be present within the current dataset and play a role in post-transcriptional regulation during infection. However, a recent study showed that WSSV-derived sRNAs (constituted $1.4 \%$ of the sRNAs sequenced in acutely infected Chinese shrimp P. chinensis, and only a minor proportion (3.6\%) of these were identified as potential miRNAs originating from pre-miRNA structures. The majority of WSSV sRNAs were likely to be short interfering RNAs (siRNAs) [120]. Given the low abundance of WSSV sRNAs that correspond to miRNAs, it may be that a greater sequencing depth is required to identify and quantify these miRNAs. Factors within the library preparation protocol, such as the use of a gel-free size selection protocol to purify sRNA sequences from total RNA may also have contributed to this result; with additional washes to purify the miRNA fragments possibly contributing to the loss of lowly expressed WSSV miRNAs.

Several studies have reported that the structure of viral miRNAs is similar to animal miRNAs due to the reliance on host enzymatic machinery for their production [121-123]. However, if their structures differ at all, for example as a result of non-canonical biogenesis pathways, this may lead to an absence of specific sequence features, such as $3^{\prime}$ overhangs that sequencing adapters recognise and bind to during the library preparation protocols and within prediction software. Recently, a study exploring the potential of Papillomaviruses (PVs) to produce miRNAs reported a similar lack of PV miRNAs identified using these methods, despite near-complete coverage of the virus genome sequences by sRNA reads [124]. In the present study, a similar high breadth of coverage of the WSSV genome $(96.2 \%)$ was observed within the sequenced reads. After reanalysis of the data used in previous publications in support of the existence of PV miRNAs, Chirayil et al. [124] detected no PV miRNA candidates, indicating that the differences seen were due to differences in the bioinformatics analyses, such as increased sequencing error and small nucleotide polymorphism allowance leading to false alignments and downstream prediction. If PVs and WSSV are able to encode miRNAs, their sequences may therefore be non-canonical and not easily identified using presently available tools. Due to the high diversity among viral genomes, both homology-based and machine-learning algorithms perform poorly in the identification of viral miRNAs [125]. 
Currently, identified miRNAs derive mainly from viruses with dsDNA genomes, therefore, it is reasonable to expect that WSSV would possess the ability to produce these also. In lymphoma cells heavily infected with Kaposi's Sarcoma-Associated Herpesvirus (KSHV), the few viral miRNAs identified accounted for at least $80 \%$ of all miRNAs [126]; therefore, it is surprising that no WSSV miRNAs were identified here. It is still debated whether other viruses such as (Human Immunodeficiency Virus) HIV-1 are able to produce their own miRNAs (reviewed by Balasubramaniam, Pandhara and Dash [127]) due to the lack of suitable protocols for their identification. Crucially, miRNAs require experimental validation prior to deposition within publicly available databases and many viral miRNAs currently lack this. WSSV miRNA sequencing studies rarely present evidence of the ability of these to fold into bifurcated hairpin precursor structures $[118,120]$, which is required evidence when establishing bona fide miRNAs. Therefore, in the absence of experimental evidence confirming the existence of WSSV-derived miRNAs, it remains unclear if this virus generates miRNA during infection in our test species.

\section{References}

1. Food and Agriculture Organization (FAO). FAO Yearbook—Fishery and Aquaculture Statistics 2018/FAO Annuaire: Statistiques des Pêches et de L'aquaculture 2018/FAO Anuario. EstadEIacute; Sticas de Pesca y Acuicultura 2018; Food and Agriculture Organization: Rome, Italy, 2020.

2. Stentiford, G.; Neil, D.; Peeler, E.; Shields, J.; Small, H.; Flegel, T.; Vlak, J.; Jones, B.; Morado, F.; Moss, S.; et al. Disease will limit future food supply from the global crustacean fishery and aquaculture sectors. J. Invertebr. Pathol. 2012, 110, 141-157. [CrossRef] [PubMed]

3. Anderson, J.L.; Valderrama, D.; Jory, D.E. GOAL 2017: Global Shrimp Production Review and Forecast. Available online: https:/ / www.aquaculturealliance.org/advocate/goal-2017-shrimp-production-survey/ (accessed on 28 April 2021).

4. Flegel, T.W. Historic emergence, impact and current status of shrimp pathogens in Asia. J. Invertebr. Pathol. 2012, 110, 166-173. [CrossRef] [PubMed]

5. Lightner, D.V. A Handbook of Pathology and Diagnostic Procedures for Diseases of Penaeid Shrimp; World Aquaculture Society: Baton Rouge, LA, USA, 1996.

6. Chai, C.Y.; Yoon, J.; Lee, Y.S.; Kim, Y.B.; Choi, T.-J. Analysis of the complete nucleotide sequence of a white spot syndrome virus isolated from pacific white shrimp. J. Microbiol. 2013, 51, 695-699. [CrossRef] [PubMed]

7. Kumar, K.V.; Shekhar, M.S.; Otta, S.K.; Karthic, K.; Kumar, J.A.; Gopikrishna, G.; Vijayan, K.K. First Report of a Complete Genome Sequence of White spot syndrome virus from India. Genome Announc. 2018, 6, 1-2. [CrossRef]

8. Rodriguez-Anaya, L.Z.; Gonzalez-Galaviz, J.R.; Casillas-Hernandez, R.; Lares-Villa, F.; Estrada, K.; Ibarra-Gamez, J.C.; SanchezFlores, A. Draft Genome Sequence of White Spot Syndrome Virus Isolated from Cultured Litopenaeus vannamei in Mexico. Genome Announc. 2016, 4, 01674-15. [CrossRef] [PubMed]

9. Restrepo, L.; Reyes, A.; Bajaña, L.; Betancourt, I.; Bayot, B. Draft Genome Sequence of a White Spot Syndrome Virus Isolate Obtained in Ecuador. Genome Announc. 2018, 6, 1-2. [CrossRef]

10. Oakey, H.J.; Smith, C.S. Complete genome sequence of a white spot syndrome virus associated with a disease incursion in Australia. Aquaculture 2018, 484, 152-159. [CrossRef]

11. Li, F.; Gao, M.; Xu, L.; Yang, F. Comparative genomic analysis of three white spot syndrome virus isolates of different virulence. Virus Genes 2016, 53, 249-258. [CrossRef]

12. Jiang, L.; Xiao, J.; Liu, L.; Pan, Y.; Yan, S.; Wang, Y. Characterization and prevalence of a novel white spot syndrome viral genotype in naturally infected wild crayfish, Procambarus clarkii, in Shanghai, China. VirusDisease 2017, 28, 250-261. [CrossRef] [PubMed]

13. Han, Y.; Li, F.; Xu, L.; Yang, F. A VP24-truncated isolate of white spot syndrome virus is inefficient in per os infection. Vet. Res. 2017, 48, 87. [CrossRef]

14. Muir, P.; Li, S.; Lou, S.; Wang, D.; Spakowicz, D.J.; Salichos, L.; Zhang, J.; Weinstock, G.M.; Isaacs, F.; Rozowsky, J.; et al. The real cost of sequencing: Scaling computation to keep pace with data generation. Genome Biol. 2016, 17, 53. [CrossRef] [PubMed]

15. Chen, X.; Zeng, D.; Chen, X.; Xie, D.; Zhao, Y.; Yang, C.; Li, Y.; Ma, N.; Li, M.; Yang, Q.; et al. Transcriptome Analysis of Litopenaeus vannamei in Response to White Spot Syndrome Virus Infection. PLoS ONE 2013, 8, e73218. [CrossRef]

16. Gonçalves, P.; Guertler, C.; Bachère, E.; De Souza, C.R.; Rosa, R.D.; Perazzolo, L.M. Molecular signatures at imminent death: Hemocyte gene expression profiling of shrimp succumbing to viral and fungal infections. Dev. Comp. Immunol. 2014, 42, $294-301$. [CrossRef]

17. Peruzza, L.; Shekhar, M.S.; Kumar, K.V.; Swathi, A.; Karthic, K.; Hauton, C.; Vijayan, K.K. Temporal changes in transcriptome profile provide insights of White Spot Syndrome Virus infection in Litopenaeus vannamei. Sci. Rep. 2019, 9, 13509. [CrossRef]

18. Santos, C.A.; Andrade, S.; Teixeira, A.K.; Farias, F.; Kurkjian, K.; Guerrelhas, A.C.; Rocha, J.L.; Galetti, P.M.J.; Freitas, P.D. Litopenaeus vannamei Transcriptome Profile of Populations Evaluated for Growth Performance and Exposed to White Spot Syndrome Virus (WSSV). Front. Genet. 2018, 9, 120. [CrossRef] 
19. Xue, S.; Liu, Y.; Zhang, Y.; Sun, Y.; Geng, X.; Sun, J. Sequencing and De Novo Analysis of the Hemocytes Transcriptome in Litopenaeus vannamei Response to White Spot Syndrome Virus Infection. PLoS ONE 2013, 8, e76718. [CrossRef] [PubMed]

20. Zhong, S.; Mao, Y.; Wang, J.; Liu, M.; Zhang, M.; Su, Y. Transcriptome analysis of Kuruma shrimp (Marsupenaeus japonicus) hepatopancreas in response to white spot syndrome virus (WSSV) under experimental infection. Fish Shellfish Immunol. 2017, 70, 710-719. [CrossRef] [PubMed]

21. Li, S.; Zhang, X.; Sun, Z.; Li, F.; Xiang, J. Transcriptome Analysis on Chinese Shrimp Fenneropenaeus chinensis during WSSV Acute Infection. PLoS ONE 2013, 8, e58627. [CrossRef]

22. Shi, X.; Meng, X.; Kong, J.; Luan, S.; Luo, K.; Cao, B.; Lu, X.; Li, X.; Chen, B.; Cao, J. Transcriptome analysis of 'Huanghai No. 2' Fenneropenaeus chinensis response to WSSV using RNA-seq. Fish Shellfish Immunol. 2018, 75, 132-138. [CrossRef] [PubMed]

23. Chang, P.; Lo, C.-F.; Wang, Y.; Kou, G. Identification of white spot syndrome associated baculovirus (WSBV) target organs in the shrimp Penaeus monodon by in situ hybridization. Dis. Aquat. Org. 1996, 27, 131-139. [CrossRef]

24. Yang, G.; Yang, L.; Zhao, Z.; Wang, J.; Zhang, X. Signature miRNAs Involved in the Innate Immunity of Invertebrates. PLoS ONE 2012, 7, e39015. [CrossRef]

25. Iorio, M.V.; Ferracin, M.; Liu, C.-G.; Veronese, A.; Spizzo, R.; Sabbioni, S.; Magri, E.; Pedriali, M.; Fabbri, M.; Campiglio, M.; et al. MicroRNA Gene Expression Deregulation in Human Breast Cancer. Cancer Res. 2005, 65, 7065-7070. [CrossRef]

26. Löfgren, S.; Frostegard, J.; Truedsson, L.; Pons-Estel, B.; D'Alfonso, S.; Witte, T.; Lauwerys, B.R.; Endreffy, E.; Kovács, L.; Vasconcelos, C.; et al. Genetic association of miRNA-146a with systemic lupus erythematosus in Europeans through decreased expression of the gene. Genes Immun. 2012, 13, 268-274. [CrossRef]

27. Martins, M.; Rosa, A.; Guedes, L.C.; Fonseca, B.V.; Gotovac, K.; Violante, S.; Mestre, T.; Coelho, M.; Rosa, M.M.; Martin, E.R.; et al. Convergence of miRNA Expression Profiling, $\alpha$-Synuclein Interacton and GWAS in Parkinson's Disease. PLoS ONE 2011, 6, e25443. [CrossRef] [PubMed]

28. Yanaihara, N.; Caplen, N.; Bowman, E.; Seike, M.; Kumamoto, K.; Yi, M.; Stephens, R.M.; Okamoto, A.; Yokota, J.; Tanaka, T.; et al. Unique microRNA molecular profiles in lung cancer diagnosis and prognosis. Cancer Cell 2006, 9, 189-198. [CrossRef]

29. Bai, X.T.; Nicot, C. miR-28-3p Is a Cellular Restriction Factor That Inhibits Human T Cell Leukemia Virus, Type 1 (HTLV-1) Replication and Virus Infection. J. Biol. Chem. 2015, 290, 5381-5390. [CrossRef] [PubMed]

30. Huang, J.; Wang, F.; Argyris, E.; Chen, K.; Liang, Z.; Tian, H.; Huang, W.; Squires, K.; Verlinghieri, G.; Zhang, H. Cellular microRNAs contribute to HIV-1 latency in resting primary CD4+ T lymphocytes. Nat. Med. 2007, 13, 1241-1247. [CrossRef] [PubMed]

31. Lecellier, C.-H.; Dunoyer, P.; Arar, K.; Lehmann-Che, J.; Eyquem, S.; Himber, C.; Saïb, A.; Voinnet, O. A Cellular MicroRNA Mediates Antiviral Defense in Human Cells. Science 2005, 308, 557-560. [CrossRef] [PubMed]

32. Trobaugh, D.; Gardner, C.L.; Sun, C.; Haddow, A.D.; Wang, E.; Chapnik, E.; Mildner, A.; Weaver, S.C.; Ryman, K.D.; Klimstra, W.B. RNA viruses can hijack vertebrate microRNAs to suppress innate immunity. Nat. Cell Biol. 2014, 506, 245-248. [CrossRef]

33. Wang, Y.-Q.; Ouyang, W.; Pan, Q.-X.; Wang, X.-M.; Xia, X.-X.; Bi, Z.-W. Overexpression of microRNA gga-miR-21 in chicken fibroblasts suppresses replication of infectious bursal disease virus through inhibiting VP1 translation. Antivir. Res. 2013, 100, 196-201. [CrossRef]

34. Zheng, J.; Cao, J.; Mao, Y.; Su, Y.; Wang, J. Identification of microRNAs with heat stress responsive and immune properties in Marsupenaeus japonicus based on next-generation sequencing and bioinformatics analysis: Essential regulators in the heat stress-host interactions. Fish Shellfish Immunol. 2018, 81, 390-398. [CrossRef] [PubMed]

35. Li, X.; Meng, X.; Luo, K.; Luan, S.; Shi, X.; Cao, B.; Kong, J. The identification of microRNAs involved in the response of Chinese shrimp Fenneropenaeus chinensis to white spot syndrome virus infection. Fish Shellfish Immunol. 2017, 68, 220-231. [CrossRef] [PubMed]

36. Kaewkascholkul, N.; Somboonviwat, K.; Asakawa, S.; Hirono, I.; Tassanakajon, A.; Somboonwiwat, K. Shrimp miRNAs regulate innate immune response against white spot syndrome virus infection. Dev. Comp. Immunol. 2016, 60, 191-201. [CrossRef] [PubMed]

37. Shekhar, M.; Karthic, K.; Kumar, K.V.; Kumar, J.A.; Swathi, A.; Hauton, C.; Peruzza, L.; Vijayan, K. Comparative analysis of shrimp (Penaeus vannamei) miRNAs expression profiles during WSSV infection under experimental conditions and in pond culture. Fish Shellfish Immunol. 2019, 93, 288-295. [CrossRef]

38. Sun, X.; Liu, Q.-H.; Yang, B.; Huang, J. Differential expression of microRNAs of Litopenaeus vannamei in response to different virulence WSSV infection. Fish Shellfish Immunol. 2016, 58, 18-23. [CrossRef]

39. Wu, W.; Dai, C.; Duan, X.; Wang, C.; Lin, X.; Ke, J.; Wang, Y.; Zhang, X.; Liu, H. miRNAs induced by white spot syndrome virus involve in immunity pathways in shrimp Litopenaeus vannamei. Fish Shellfish Immunol. 2019, 93, 743-751. [CrossRef]

40. Zhao, M.-R.; Meng, C.; Xie, X.-L.; Li, C.-H.; Liu, H.-P. Characterization of microRNAs by deep sequencing in red claw crayfish Cherax quadricarinatus haematopoietic tissue cells after white spot syndrome virus infection. Fish Shellfish Immunol. 2016, 59, 469-483. [CrossRef]

41. Yang, H.; Li, X.; Ji, J.; Yuan, C.; Gao, X.; Zhang, Y.; Lu, C.; Li, F.; Zhang, X. Changes of microRNAs expression profiles from red swamp crayfish (Procambarus clarkia) hemolymph exosomes in response to WSSV infection. Fish Shellfish Immunol. 2019, 84, 169-177. [CrossRef]

42. Ching, T.; Huang, S.; Garmire, L.X. Power analysis and sample size estimation for RNA-Seq differential expression. RNA 2014, 20, 1684-1696. [CrossRef] 
43. Bateman, K.; Munro, J.; Uglow, B.; Small, H.; Stentiford, G. Susceptibility of juvenile European lobster Homarus gammarus to shrimp products infected with high and low doses of white spot syndrome virus. Dis. Aquat. Org. 2012, 100, 169-184. [CrossRef]

44. Durand, S.V.; Lightner, D.V. Quantitative real time PCR for the measurement of white spot syndrome virus in shrimp. J. Fish Dis. 2002, 25, 381-389. [CrossRef]

45. Bolger, A.M.; Lohse, M.; Usadel, B. Trimmomatic: A flexible trimmer for Illumina sequence data. Bioinformatics 2014, 30, 2114-2120. [CrossRef]

46. Grabherr, M.G.; Haas, B.J.; Yassour, M.; Levin, J.Z.; Thompson, D.; Amit, I.; Adiconis, X.; Fan, L.; Raychowdhury, R.; Zeng, Q.; et al. Full-length transcriptome assembly from RNA-Seq data without a reference genome. Nat. Biotechnol. 2011, 29, 644-652. [CrossRef]

47. Fu, L.; Niu, B.; Zhu, Z.; Wu, S.; Li, W. CD-HIT: Accelerated for clustering the next-generation sequencing data. Bioinformatics 2012, 28, 3150-3152. [CrossRef]

48. Simão, F.A.; Waterhouse, R.M.; Ioannidis, P.; Kriventseva, E.V.; Zdobnov, E.M. BUSCO: Assessing genome assembly and annotation completeness with single-copy orthologs. Bioinformatics 2015, 31, 3210-3212. [CrossRef]

49. Buchfink, B.; Xie, C.; Huson, D.H. Fast and sensitive protein alignment using DIAMOND. Nat. Methods 2015, 12, 59-60. [CrossRef] [PubMed]

50. Huson, D.H.; Beier, S.; Flade, I.; Górska, A.; El-Hadidi, M.; Mitra, S.; Ruscheweyh, H.-J.; Tappu, R. MEGAN Community Edition-Interactive Exploration and Analysis of Large-Scale Microbiome Sequencing Data. PLoS Comput. Biol. 2016, 12 , e1004957. [CrossRef] [PubMed]

51. Langmead, B.; Trapnell, C.; Pop, M.; Salzberg, S.L. Ultrafast and memory-efficient alignment of short DNA sequences to the human genome. Genome Biol. 2009, 10, R25. [CrossRef]

52. Li, B.; Dewey, C.N. RSEM: Accurate transcript quantification from RNA-Seq data with or without a reference genome. BMC Bioinform. 2011, 12, 323. [CrossRef] [PubMed]

53. Robinson, M.D.; McCarthy, D.J.; Smyth, G.K. edgeR: A Bioconductor package for differential expression analysis of digital gene expression data. Bioinformatics 2010, 26, 139-140. [CrossRef]

54. Benjamini, Y.; Hochberg, Y. Controlling the false discovery rate: A practical and powerful approach to multiple testing. J. R. Stat. Soc. Ser. B 1995, 57, 289-300. [CrossRef]

55. Conesa, A.; Götz, S.; García-Gómez, J.M.; Terol, J.; Talón, M.; Robles, M. Blast2GO: A universal tool for annotation, visualization and analysis in functional genomics research. Bioinformatics 2005, 21, 3674-3676. [CrossRef] [PubMed]

56. Subramanian, A.; Tamayo, P.; Mootha, V.K.; Mukherjee, S.; Ebert, B.L.; Gillette, M.A.; Paulovich, A.; Pomeroy, S.L.; Golub, T.R.; Lander, E.S.; et al. Gene set enrichment analysis: A knowledge-based approach for interpreting genome-wide expression profiles. Proc. Natl. Acad. Sci. USA 2005, 102, 15545-15550. [CrossRef] [PubMed]

57. Moriya, Y.; Itoh, M.; Okuda, S.; Yoshizawa, A.C.; Kanehisa, M. KAAS: An automatic genome annotation and pathway reconstruction server. Nucleic Acids Res. 2007, 35, W182-W185. [CrossRef] [PubMed]

58. Luo, W.; Friedman, M.S.; Shedden, K.; Hankenson, K.D.; Woolf, P.J. GAGE: Generally applicable gene set enrichment for pathway analysis. BMC Bioinform. 2009, 10, 161. [CrossRef] [PubMed]

59. R Core Team. R: A Language and Environment for Statistical Computing. Available online: http//www.R-project.org/ (accessed on 28 April 2021).

60. Luo, W.; Brouwer, C. Pathview: An R/Bioconductor package for pathway-based data integration and visualization. Bioinformatics 2013, 29, 1830-1831. [CrossRef]

61. Yang, F.; He, J.; Lin, X.; Li, Q.; Pan, D.; Zhang, X.; Xu, X. Complete Genome Sequence of the Shrimp White Spot Bacilliform Virus. J. Virol. 2001, 75, 11811-11820. [CrossRef]

62. Langmead, B.; Salzberg, S.L. Fast gapped-read alignment with Bowtie 2. Nat. Methods 2012, 9, 357-359. [CrossRef]

63. Martin, M. Cutadapt removes adapter sequences from high-throughput sequencing reads. EMBnet. J. 2011, 17, 10-12. [CrossRef]

64. Li, H.; Handsaker, B.; Wysoker, A.; Fennell, T.; Ruan, J.; Homer, N.; Marth, G.; Abecasis, G.; Durbin, R. The Sequence Alignment/Map format and SAMtools. Bioinformatics 2009, 25, 2078-2079. [CrossRef]

65. Seqtk: Toolkit for Processing Sequences in FASTA/Q Formats. Available online: https://github.com/lh3/seqtk (accessed on 25 October 2020).

66. Pertea, G. gpertea/fqtrim: Fqtrim Release (Version v0.9.7). Zenodo. Available online: https://doi.org/10.5281/zenodo.1185412 (accessed on 28 April 2021).

67. Friedlander, M.; Mackowiak, S.; Li, N.; Chen, W.; Rajewsky, N. miRDeep2 accurately identifies known and hundreds of novel microRNA genes in seven animal clades. Nucleic Acids Res. 2011, 40, 37-52. [CrossRef]

68. Zhang, X.; Yuan, J.; Sun, Y.; Li, S.; Gao, Y.; Yu, Y.; Liu, C.; Wang, Q.; Lv, X.; Zhang, X.; et al. Penaeid shrimp genome provides insights into benthic adaptation and frequent molting. Nat. Commun. 2019, 10, 356. [CrossRef] [PubMed]

69. Fromm, B.; Domanska, D.; Høye, E.; Ovchinnikov, V.; Kang, W.; Aparicio-Puerta, E.; Johansen, M.; Flatmark, K.; Mathelier, A.; Hovig, E.; et al. MirGeneDB 2.0: The metazoan microRNA complement. Nucleic Acids Res. 2020, 48, D132-D141. [CrossRef] [PubMed]

70. Huang, T.; Xu, D.; Zhang, X. Characterization of host microRNAs that respond to DNA virus infection in a crustacean. BMC Genom. 2012, 13, 159. [CrossRef] [PubMed] 
71. Camacho, C.; Coulouris, G.; Avagyan, V.; Ma, N.; Papadopoulos, J.S.; Bealer, K.; Madden, T.L. BLAST+: Architecture and applications. BMC Bioinform. 2009, 10, 421. [CrossRef]

72. He, P.; Wei, P.; Zhang, B.; Zhao, Y.; Li, Q.; Chen, X.; Zeng, D.; Peng, M.; Yang, C.; Peng, J.; et al. Identification of microRNAs involved in cold adaptation of Litopenaeus vannamei by high-throughput sequencing. Gene 2018, 677, 24-31. [CrossRef]

73. Love, M.I.; Huber, W.; Anders, S. Moderated estimation of fold change and dispersion for RNA-seq data with DESeq2. Genome Biol. 2014, 15, 550. [CrossRef]

74. Hofacker, I.L. Vienna RNA secondary structure server. Nucleic Acids Res. 2003, 31, 3429-3431. [CrossRef] [PubMed]

75. Bonnet, E.; Wuyts, J.; Rouzé, P.; Van De Peer, Y. Evidence that microRNA precursors, unlike other non-coding RNAs, have lower folding free energies than random sequences. Bioinformatics 2004, 20, 2911-2917. [CrossRef] [PubMed]

76. Enright, A.J.; John, B.; Gaul, U.; Tuschl, T.; Sander, C.; Marks, D.S. MicroRNA targets in Drosophila. Genome Biol. 2003,5 , R1. [CrossRef] [PubMed]

77. Miranda, K.C.; Huynh, T.; Tay, Y.; Ang, Y.-S.; Tam, W.L.; Thomson, A.M.; Lim, B.; Rigoutsos, I. A Pattern-Based Method for the Identification of MicroRNA Binding Sites and Their Corresponding Heteroduplexes. Cell 2006, 126, 1203-1217. [CrossRef] [PubMed]

78. Oliveira, A.C.; Bovolenta, L.A.; Nachtigall, P.G.; Herkenhoff, M.; Lemke, N.; Pinhal, D. Combining Results from Distinct MicroRNA Target Prediction Tools Enhances the Performance of Analyses. Front. Genet. 2017, 8, 59. [CrossRef] [PubMed]

79. Wickham, H. ggplot2: Elegant Graphics for Data Analysis; Springer: New York, NY, USA, 2016.

80. Farrants, A.-K.Ö. Chromatin remodelling and actin organisation. FEBS Lett. 2008, 582, 2041-2050. [CrossRef]

81. Tang, L.; Nogales, E.; Ciferri, C. Structure and function of SWI/SNF chromatin remodeling complexes and mechanistic implications for transcription. Prog. Biophys. Mol. Biol. 2010, 102, 122-128. [CrossRef] [PubMed]

82. Chen, I.-T.; Aoki, T.; Huang, Y.-T.; Hirono, I.; Chen, T.-C.; Huang, J.-Y.; Chang, G.-D.; Lo, C.-F.; Wang, H.-C. White Spot Syndrome Virus Induces Metabolic Changes Resembling the Warburg Effect in Shrimp Hemocytes in the Early Stage of Infection. J. Virol. 2011, 85, 12919-12928. [CrossRef]

83. Suhyuen, L.; Huang, Y.-T.; Chen, I.-T.; Lee, D.-Y.; Hsieh, Y.-C.; Li, C.-Y.; Geendong, C.; Liang, S.-Y.; Lin, S.-Y.; Huang, S.-W.; et al. An Invertebrate Warburg Effect: A Shrimp Virus Achieves Successful Replication by Altering the Host Metabolome via the PI3K-Akt-mTOR Pathway. PLOS Pathog. 2014, 10, e1004196. [CrossRef]

84. Brand, M. Uncoupling to survive? The role of mitochondrial inefficiency in ageing. Exp. Gerontol. 2000, 35, 811-820. [CrossRef]

85. McCallum, K.C.; Garsin, D.A. The Role of Reactive Oxygen Species in Modulating the Caenorhabditis elegans Immune Response. PLOS Pathog. 2016, 12, e1005923. [CrossRef]

86. Wang, Z.; Sun, B.; Zhu, F. The shrimp hormone receptor acts as an anti-apoptosis and anti-inflammatory factor in innate immunity. Fish Shellfish Immunol. 2018, 72, 581-592. [CrossRef]

87. Apitanyasai, K.; Huang, S.-W.; Ng, T.H.; He, S.-T.; Huang, Y.-H.; Chiu, S.-P.; Tseng, K.-C.; Lin, S.-S.; Chang, W.-C.; Baldwin-Brown, J.G.; et al. The gene structure and hypervariability of the complete Penaeus monodon Dscam gene. Sci. Rep. 2019, 9, 16595. [CrossRef]

88. Fu, L.-L.; Li, T.-P.; Wang, Y. Potential role of LvDscam in specific immune response of Litopenaeus vannamei against white spot syndrome virus by oral delivery of VP28 using Bacillus subtilis. Aquac. Res. 2014, 47, 2068-2079. [CrossRef]

89. Chen, R.-Y.; Shen, K.-L.; Chen, Z.; Fan, W.-W.; Xie, X.-L.; Meng, C.; Chang, X.-J.; Zheng, L.-B.; Jeswin, J.; Li, C.-H.; et al. White spot syndrome virus entry is dependent on multiple endocytic routes and strongly facilitated by Cq-GABARAP in a CME-dependent manner. Sci. Rep. 2016, 6, 28694. [CrossRef]

90. Huang, J.; Li, F.; Wu, J.; Yang, F. White spot syndrome virus enters crayfish hematopoietic tissue cells via clathrin-mediated endocytosis. Virology 2015, 486, 35-43. [CrossRef] [PubMed]

91. Huang, Z.-J.; Kang, S.-T.; Leu, J.-H.; Chen, L.-L. Endocytic pathway is indicated for white spot syndrome virus (WSSV) entry in shrimp. Fish Shellfish Immunol. 2013, 35, 707-715. [CrossRef] [PubMed]

92. Liu, B.; Tang, X.; Zhan, W. Interaction between white spot syndrome virus VP26 and hemocyte membrane of shrimp, Fenneropenaeus chinensis. Aquaculture 2011, 314, 13-17. [CrossRef]

93. Schudt, G.; Dolnik, O.; Kolesnikova, L.; Biedenkopf, N.; Herwig, A.; Becker, S. Transport of Ebolavirus Nucleocapsids Is Dependent on Actin Polymerization: Live-Cell Imaging Analysis of Ebolavirus-Infected Cells. J. Infect. Dis. 2015, 212, S160-S166. [CrossRef]

94. Li, S.; Li, F.; Sun, Z.; Zhang, X.; Xiang, J. Differentially proteomic analysis of the Chinese shrimp at WSSV latent and acute infection stages by iTRAQ approach. Fish Shellfish Immunol. 2016, 54, 629-638. [CrossRef]

95. Sun, B.; Wang, Z.; Wang, Z.; Ma, X.; Zhu, F. A Proteomic Study of Hemocyte Proteins from Mud Crab (Scylla paramamosain) Infected with White Spot Syndrome Virus or Vibrio alginolyticus. Front. Immunol. 2017, 8, 468. [CrossRef]

96. Syamaladevi, D.P.; Spudich, J.A.; Sowdhamini, R. Structural and Functional Insights on the Myosin Superfamily. Bioinform. Biol. Insights 2012, 6, 11-21. [CrossRef] [PubMed]

97. Han, F.; Wang, Z.; Wang, X. Characterization of myosin light chain in shrimp hemocytic phagocytosis. Fish Shellfish Immunol. 2010, 29, 875-883. [CrossRef]

98. Wang, Z.; Zhu, F. Different roles of a novel shrimp microRNA in white spot syndrome virus (WSSV) and Vibrio alginolyticus infection. Dev. Comp. Immunol. 2018, 79, 21-30. [CrossRef] 
99. Argue, B.J.; Arce, S.M.; Lotz, J.M.; Moss, S.M. Selective breeding of Pacific white shrimp (Litopenaeus vannamei) for growth and resistance to Taura Syndrome Virus. Aquaculture 2002, 204, 447-460. [CrossRef]

100. Meng, X.; Shi, X.; Kong, J.; Luan, S.; Luo, K.; Cao, B.; Liu, N.; Lu, X.; Li, X.; Deng, K.; et al. Influence of white spot syndrome virus infection on hepatopancreas gene expression of 'Huanghai No. 2' shrimp (Fenneropenaeus chinensis). J. Ocean Univ. China 2017, 16, 863-872. [CrossRef]

101. Li, W.; Desmarets, L.M.B.; De Gryse, G.M.A.; Theuns, S.; Van Tuan, V.; Van Thuong, K.; Bossier, P.; Nauwynck, H.J. Virus replication cycle of white spot syndrome virus in secondary cell cultures from the lymphoid organ of Litopenaeus vannamei. J. Gen. Virol. 2015, 96, 2844-2854. [CrossRef]

102. Pavelin, J.; Mccormick, D.; Chiweshe, S.; Ramachandran, S.; Lin, Y.-T.; Grey, F. Cellular v-ATPase is required for virion assembly compartment formation in human cytomegalovirus infection. Open Biol. 2017, 7. [CrossRef]

103. Kohio, H.P.; Adamson, A.L. Glycolytic control of vacuolar-type ATPase activity: A mechanism to regulate influenza viral infection. Virology 2013, 444, 301-309. [CrossRef] [PubMed]

104. Chen, I.-T.; Lee, D.-Y.; Huang, Y.-T.; Kou, G.-H.; Wang, H.-C.; Chang, G.-D.; Lo, C.-F. Six Hours after Infection, the Metabolic Changes Induced by WSSV Neutralize the Host's Oxidative Stress Defenses. Sci. Rep. 2016, 6, 27732. [CrossRef]

105. Leu, J.-H.; Lin, S.-J.; Huang, J.-Y.; Chen, T.-C.; Lo, C.-F. A model for apoptotic interaction between white spot syndrome virus and shrimp. Fish Shellfish Immunol. 2013, 34, 1011-1017. [CrossRef]

106. El-Bacha, T.; Da Poian, A. Virus-induced changes in mitochondrial bioenergetics as potential targets for therapy. Int. J. Biochem. Cell Biol. 2013, 45, 41-46. [CrossRef]

107. Zuo, D.; Wu, D.-L.; Ma, C.-A.; Li, H.-X.; Huang, Y.-H.; Wang, D.-L.; Zhao, Y.-L. Effects of white spot syndrome virus infection and role of immune polysaccharides of juvenile Cherax quadricarinatus. Aquaculture 2015, 437, 235-242. [CrossRef]

108. O'Brien, J.; Hayder, H.; Zayed, Y.; Peng, C. Overview of MicroRNA Biogenesis, Mechanisms of Actions, and Circulation. Front. Endocrinol. 2018, 9, 402. [CrossRef]

109. Lu, M.; Zhang, P.-J.; Li, C.-H.; Lv, Z.-M.; Zhang, W.-W.; Jin, C.-H. miRNA-133 augments coelomocyte phagocytosis in bacteriachallenged Apostichopus japonicus via targeting the TLR component of IRAK-1 in vitro and in vivo. Sci. Rep. 2015, 5, 12608. [CrossRef] [PubMed]

110. Liu, C.; Wang, J.; Zhang, X. The Involvement of MiR-1-Clathrin Pathway in the Regulation of Phagocytosis. PLoS ONE 2014, 9 e98747. [CrossRef]

111. Ng, T.H.; Chiang, Y.-A.; Yeh, Y.-C.; Wang, H.-C. Review of Dscam-mediated immunity in shrimp and other arthropods. Dev. Comp. Immunol. 2014, 46, 129-138. [CrossRef]

112. Chou, P.-H.; Chang, H.-S.; Chen, I.-T.; Lin, H.-Y.; Chen, Y.-M.; Yang, H.-L.; Wang, K.H.-C. The putative invertebrate adaptive immune protein Litopenaeus vannamei Dscam (LvDscam) is the first reported Dscam to lack a transmembrane domain and cytoplasmic tail. Dev. Comp. Immunol. 2009, 33, 1258-1267. [CrossRef]

113. Ng, T.H.; Kumar, R.; Apitanyasai, K.; He, S.-T.; Chiu, S.-P.; Wang, H.-C. Selective expression of a "correct cloud" of Dscam in crayfish survivors after second exposure to the same pathogen. Fish Shellfish Immunol. 2019, 92, 430-437. [CrossRef]

114. Riffo-Campos, Á.L.; Riquelme, I.; Brebi-Mieville, P. Tools for Sequence-Based miRNA Target Prediction: What to Choose? Int. J. Mol. Sci. 2016, 17, 1987. [CrossRef]

115. Wightman, B.; Ha, I.; Ruvkun, G. Posttranscriptional regulation of the heterochronic gene lin-14 by lin-4 mediates temporal pattern formation in C. elegans. Cell 1993, 75, 855-862. [CrossRef]

116. Qureshi, A.; Thakur, N.; Monga, I.; Thakur, A.; Kumar, M. VIRmiRNA: A comprehensive resource for experimentally validated viral miRNAs and their targets. Database 2014, 2014. [CrossRef]

117. Robinson, J.T.; Thorvaldsdóttir, H.; Winckler, W.; Guttman, M.; Lander, E.S.; Getz, G.; Mesirov, J.P. Integrative genomics viewer. Nat. Biotechnol. 2011, 29, 24-26. [CrossRef]

118. He, Y.; Zhang, X. Comprehensive characterization of viral miRNAs involved in white spot syndrome virus (WSSV) infection. RNA Biol. 2012, 9, 1019-1029. [CrossRef] [PubMed]

119. Huang, T.; Cui, Y.; Zhang, X.; Ross, S.R. Involvement of Viral MicroRNA in the Regulation of Antiviral Apoptosis in Shrimp. J. Virol. 2013, 88, 2544-2554. [CrossRef]

120. Liu, C.; Li, F.; Sun, Y.; Zhang, X.; Yuan, J.; Yang, H.; Xiang, J. Virus-derived small RNAs in the penaeid shrimp Fenneropenaeus chinensis during acute infection of the DNA virus WSSV. Sci. Rep. 2016, 6, 28678. [CrossRef]

121. Bakre, A.A.; Maleki, A.; Tripp, R.A. MicroRNA and Nonsense Transcripts as Putative Viral Evasion Mechanisms. Front. Cell. Infect. Microbiol. 2019, 9, 152. [CrossRef]

122. Contrant, M.; Fender, A.; Chane-Woon-Ming, B.; Randrianjafy, R.; Vivet-Boudou, V.; Richer, D.; Pfeffer, S. Importance of the RNA secondary structure for the relative accumulation of clustered viral microRNAs. Nucleic Acids Res. 2014, 42, 7981-7996. [CrossRef]

123. Kincaid, R.P.; Sullivan, C.S. Virus-Encoded microRNAs: An Overview and a Look to the Future. PLOS Pathog. 2012, 8, e1003018. [CrossRef]

124. Chirayil, R.; Kincaid, R.P.; Dahlke, C.; Kuny, C.V.; Dälken, N.; Spohn, M.; Lawson, B.; Grundhoff, A.; Sullivan, C.S. Identification of virus-encoded microRNAs in divergent Papillomaviruses. PLOS Pathog. 2018, 14, e1007156. [CrossRef]

125. Lamkiewicz, K.; Barth, E.; Barth, E.; Ibrahim, B. Identification of potential microRNAs associated with Herpesvirus family based on bioinformatic analysis. bioRxiv 2018. [CrossRef] 
126. Umbach, J.L.; Cullen, B.R. In-Depth Analysis of Kaposi's Sarcoma-Associated Herpesvirus MicroRNA Expression Provides Insights into the Mammalian MicroRNA-Processing Machinery. J. Virol. 2010, 84, 695-703. [CrossRef] [PubMed]

127. Balasubramaniam, M.; Pandhare, J.; Dash, C. Are microRNAs Important Players in HIV-1 Infection? An Update. Viruses 2018, 10, 110. [CrossRef] 